\title{
Understanding the links between social ties and fitness over the life cycle in primates
}

\author{
Nicole A. Thompson * \\ Department of Ecology, Evolution, and Environmental Biology, Columbia University, \\ New York, NY 10027, USA \\ *Author's e-mail address: gavago@gmail.com
}

Received 25 October 2017; initial decision 14 May 2018; revised 27 August 2018; accepted 22 February 2019; published online 21 March 2019

\begin{abstract}
Many studies highlight the correlation between social ties and fitness, yet often cannot reveal how ties influence fitness. This review is aimed to facilitate the formulation and testing of hypotheses in this area on non-human primates. I outline fitness-relevant measures of social ties and 6 potential pathways from ties to fitness. Pathways include communal care; group level cooperation for resources; monopolizing resources within groups; attaining social status; reducing risk and allostatic load; and developing behavioural competence. Hypotheses for further evaluation include (1) fitness increases sociality, not vice versa; (2) early life experience influences both ties and fitness, (3) ties are actually costly; (4) short term costs of ties are outweighed by long term benefits. With the advance of theoretical and methodological approaches to evaluate the costs and benefits of social ties, and monitor them at multi-generational field sites, primate behavioural ecologists are poised to test several of these hypotheses.
\end{abstract}

\section{Keywords}

social ties, bonds, connections, integration, sociality, fitness, benefits, mechanisms.

\section{Introduction}

In recent decades, research has focused on examining the adaptive benefits of differentiated, cooperative and affiliative social ties in animals, beyond the general benefits of social living (Lin \& Michener, 1972; Silk, 2007). Studies of several group-living mammals, including primates (Silk et al., 2003, 2009, 
2010b; Gilby et al., 2013; McFarland \& Majolo, 2013; Archie et al., 2014; McFarland et al., 2015; Lehmann et al., 2016; Kalbitzer et al., 2017; McFarland et al., 2017; Thompson \& Cords, 2018), rodents (Weidt et al., 2008; Yee et al., 2008), cetaceans (Foster et al., 2012; Stanton \& Mann, 2012) and ungulates (Cameron et al., 2009; Vander Wal et al., 2014; Nuñez et al., 2015) have revealed that maintaining affiliative and cooperative ties, both among same and opposite sex partners, corresponds with increased individual fitness, or increased survival and reproductive success. Despite the recent proliferation of findings that 'social ties matter', the mechanisms by which ties influence fitness are not altogether clear. This is, in part, because the length and resolution of research projects, particularly on long-lived animals, are not always sufficient to understand the precise pathways by which long-term fitness outcomes come about.

One common criticism of the assertion that social ties increase individual fitness is that such a causal relationship, if present, is actually reversed. Namely, better general health and vitality could motivate individuals to be more social, and also make individuals more attractive as social partners (Uchino, 2004). Today, several prospective studies in human biomedical research have controlled for initial health status, revealing that the relationships between social ties and fitness outcomes, like mortality and disease progression, hold regardless of initial health (Holt-Lunstad et al., 2010; Shor \& Roelfs, 2015). Health status and related processes like senescence do play a role in social behaviour and attraction between partners (e.g., Roelfs et al., 2011; Almeling et al., 2016), yet these human studies substantiate the independent effects of social ties on health and fitness outcomes. Although long-term research on non-human animals has yet to similarly control for initial health status, it appears well warranted to follow up on correlations between social ties and fitness in non-human primates to understand how ties influence fitness.

This review focuses on evidence of how social ties influence individual fitness in non-human primates (hereafter primates), with relevant evidence drawn from studies of humans and several non-primate animals. My goal in this review is to outline hypotheses on how social ties influence fitness that can either continue or begin to be evaluated by future research. I focus on ties characterized by affiliation, spatial association, and/or cooperation and also on ties that are not directly related to reproduction (e.g., monogamous pairs) but that may occur between kin. Similar to previous reviews of 'friendship' in primates (Bergman, 2010; Massen et al., 2010; Seyfarth \& Cheney, 2012), I 
discuss the quantification and function of social ties primarily among samesex partners. Unlike previous reviews, I focus on delineating pathways by which social ties can influence fitness. The pathways outlined go beyond those discussed in Ostner \& Schulke (2018) and Cords \& Thompson (2017).

The review comprises two parts: (1) the definition of social ties and their measurements that appear relevant to fitness outcomes and (2) the functional pathways by which ties potentially enhance fitness. In the first part, I also discuss variables that potentially confound correlations between ties and fitness, such as attraction to shared spaces and individual early life experience. In the second part, I outline six pathways by which evidence suggests that ties can benefit individuals and influence their fitness. In doing so, I suggest approaches for researchers to test whether relevant pathways occur in their study systems. These six pathways include communal care of offspring and allomothering; group level cooperation to acquire resources; monopolizing resources within social units; establishing, maintaining, and increasing social status; reducing exposure to risk and allostatic load, and developing social and physical competence (Figure 1).

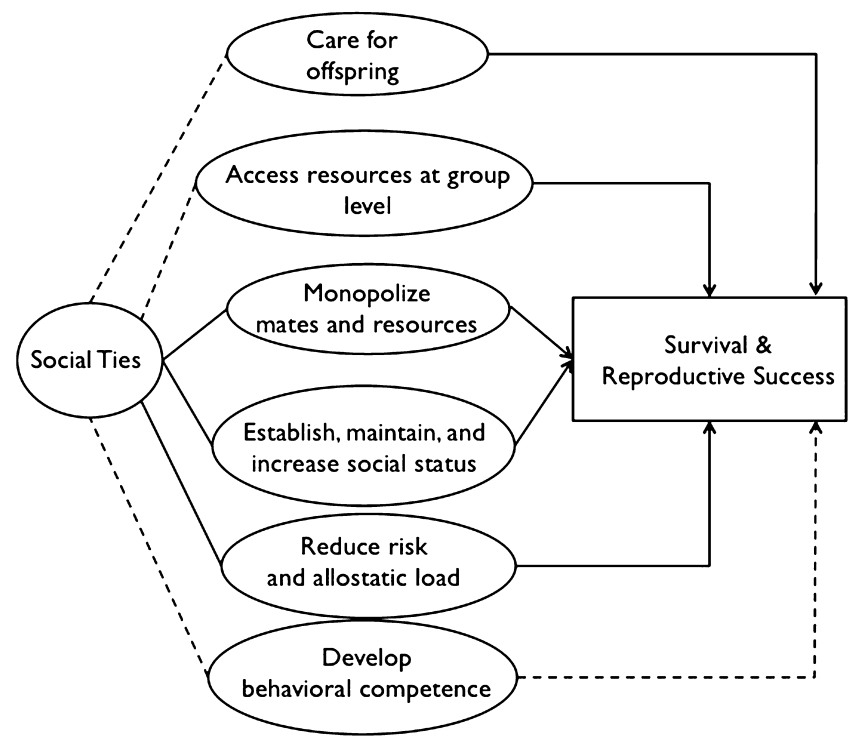

Figure 1. Proposed functional pathways by which social ties influence fitness (adapted from Cords \& Thompson, 2017). Solid lines indicate links in pathways that have been well substantiated. Dotted lines indicate links with suggestive evidence that merit further study. 


\section{Defining and measuring social ties}

\subsection{What are ties?}

In the 1970s, Robert Hinde pioneered the scientific description and classification of relationships in non-human animals (Hinde, 1976a,b) after several researchers observed that individuals of many gregarious species associate in a non-random way, and prefer to interact with certain conspecifics and to avoid others. Interactions become patterned over time, and the quality of the interactions themselves define the quality of the relationship (e.g., cooperative, affiliative, agonistic; Hinde, 1976a). In this view, friendships and associations are characterized by affiliative interactions, including spatial proximity, and non-aggressive physical contact and vocalizations. Alliances are characterized by cooperative interactions or joint efforts that achieve a mutual or reciprocated reward, such as access to food or a mate, and often occur in zero-sum contexts where individuals work together to outcompete a third party. Antagonistic and dominance relationships are characterized by agonistic and competitive interactions, including visual or vocal threats, physical aggression, chasing or fleeing, exclusion and avoidance.

Typically, ties are relationships that are perpetuated because of the quality of the affiliative interactions that define them, and not by third variables such as individual personality or mutual attraction to particular microhabitats (Dingemanse et al., 2004; Godde et al., 2013; Best et al., 2014). As an example, dyads of male chimpanzees that maintain close spatial proximity in one period of observation are more likely to do the same in future (Mitani, 2009). The time that pairs of males spend in proximity to one another correlates positively with the quality of their interactions, as measured by the equitability of their allo-grooming (hereafter grooming), suggesting that males are attracted to one another to affiliate (Mitani, 2009).

Currently, there are no universal criteria for either how stable or enduring a pattern must be to constitute a tie. Even when one controls for third variables, patterns of interaction might demonstrate 'dynamic stability' (Hinde, 1976a) or be unstable because of chance or third variables. For instance, Henzi et al. (2009) argued that female baboons in two South African populations did not form 'relationships' proper, because the short-term predictability of a dyads' spatial associations increased when food was scarce and decreased when food was abundant. The majority of females in the study populations also did not demonstrate the same partner preferences from the first foodscarce season to the second. These findings resembled a previous report that 
the identity of a female's top grooming associates changed from year to year over a four-year study (Barrett \& Henzi, 2002). Silk et al. (2006, 2010a), by contrast, found that many of a baboon female's closest spatial and grooming partners remained her closest partners for up to seven years. Unlike Barrett \& Henzi (2002), Silk et al. (2006, 2010a) allowed a 'one year gap' such that a female has a close partner for three years if her partner is close in year 1, not close in year 2, and reappears in year 3. However, the duration of strong ties did not change substantially whether excluding vs. including a one-year gap (Silk et al., 2010a). Differences in observation methods could account for differences in the length of female-female relationships among chacma baboons in South Africa vs. Botswana, e.g., scan sampling spatial association vs. focal follows capturing all social interactions (Altmann, 1974), or it is possible that females associate in different ways between these populations because of certain ecological conditions.

Ties are characterized by their structure and also by their function. Research therefore aims to measure ties in ways that are relevant to those functions. Hans Kummer (1978) described individuals as 'investing' their time and energy in a social partner because of the adaptive value of a tie with it, which can be measured in terms of inclusive fitness, mutual gain, or the potential for reciprocal exchange (Aureli et al., 2002). For example, partner value was operationalized in ravens (Fraser \& Bugnyar, 2010) and chimpanzees (Fraser et al., 2008) in terms of the frequency of grooming and agonistic support, and such value increased with kinship (also see Duboscq et al., 2017, crested macaques). The functions of ties and their adaptive value with partners are foundational to how ties potentially enhance individual fitness. Indeed, the different values of social partners - e.g., familiarity and stability of ties between kin, the mutual gain of collective acts and reciprocal exchange - appear to be non-mutually exclusive and foundational mechanisms in the pathways between social ties and fitness, as outlined in part 2. Another potentially important aspect of partner value and tie function is the potential for interchange, a process similar yet distinct from reciprocity, in which individuals trade seemingly altruistic acts in different currencies or types of behaviour, e.g., grooming for coalitionary support during aggression (Hemelrijk \& Ek, 1991; Noë \& Hammerstein, 1995; Hemelrijk et al., 1999; Watts \& Mitani, 2002; Berghänel et al., 2011; Noe \& Voelkl, 2013; Young et al., 2014b). Mechanisms involving interchange also underlie several pathways listed in part 2, e.g., investing in social ties to maintain dominance rank and to avoid harassment. 


\subsection{Social tie terminology and measures}

In the literature today, measures of individual sociality that correlate with individual fitness fall into three major categories: measures of gregariousness, bondedness, and integration (see Table 1 in Silk et al., 2013; Ostner \& Schülke, 2018). Within bondedness, three aspects that appear meaningful in a fitness context include tie strength, tie stability, and tie symmetry. Within integration, important measures are those that characterize partner diversity and position within a social network, or among indirect social ties. I explain each further below and list them in Table 1. Importantly, I discuss these measures as predictors of fitness outcomes. As response variables, or as objects of analysis themselves, social measures require special statistical methods controlling for dyadic non-independence, which go beyond the scope of this review (e.g., Gomes et al., 2009; Henzi et al., 2009; Duboscq et al., 2017; Farine, 2017).

Gregariousness refers to an individuals' general tendency to socialize in a friendly way. It is often measured by (1) an individual's social activity budget, i.e., the proportion of observation time spent in association or affiliation with one or more partners; and (2) its rates of affiliation given to and received from any partner relative to that of the average individual (e.g., composite sociality index, CSI, Sapolsky et al., 1997; Silk et al., 2003; Cameron et al., 2009; Archie et al., 2014). Although simple measures of gregarious are sometimes useful to capture a large-scale trend, their simplicity is also a potential drawback as they do not capture a precise affiliative strategy among differentiated social ties.

Bondedness is fundamentally a quality of a dyad, but can be translated to describe the tendencies of an individual. Tie strength, the first of three discussed aspects bondedness, is usually calculated as the observed rates of affiliation and/or spatial association between two partners relative to their opportunities to encounter one another (Cairns \& Schwager, 1987; Mitani, 2009), or by affiliative rates relative to rates of aggression given and received (e.g., relationship quality index, Weaver \& de Waal, 2003). Affiliative rates are often further expressed relative to the rates of an average dyad in a dyadic composite sociality index or DSI (Schülke et al., 2010; Silk et al., 2013; Young et al., 2014b). One pitfall of the DSI is that tie strengths below average range from 0 up to 1 , whereas above average tie strengths range from 1 to infinity. This inequality potentially gives undue weight to above average DSIs 


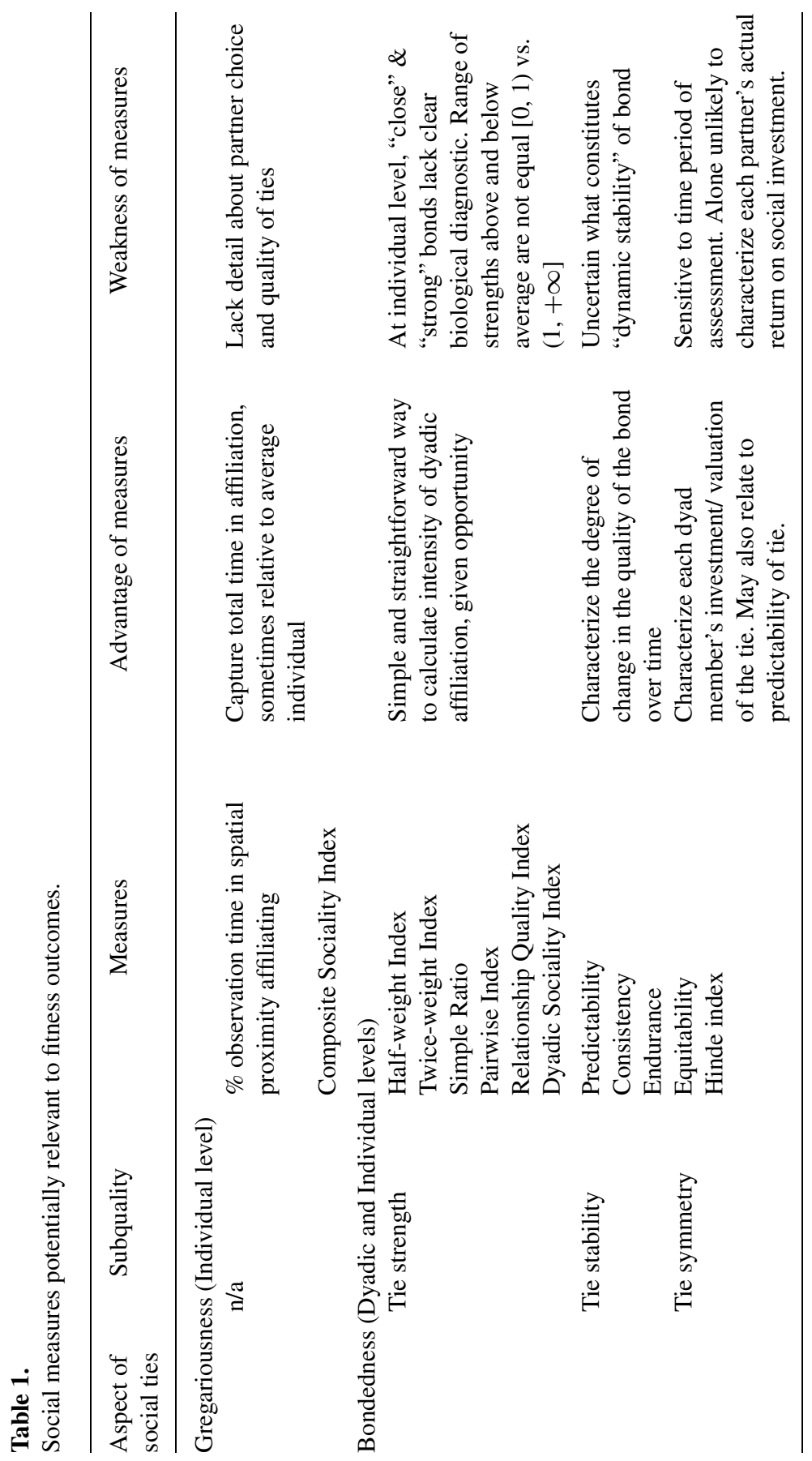




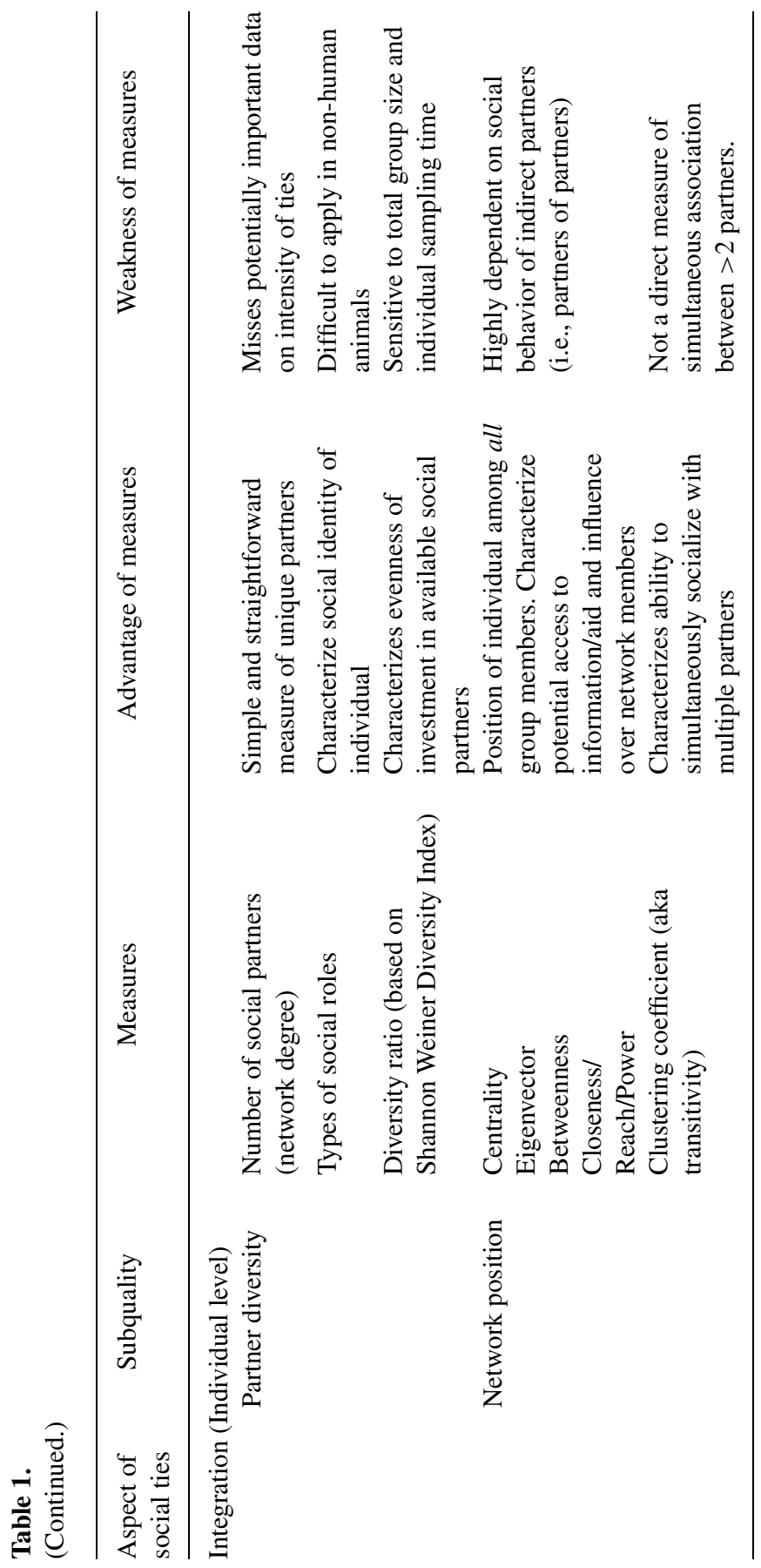


in analyses. One solution to this is linearizing DSIs by taking their log values. Instituting this method now, however, may hinder comparisons between new and previous studies. A further note of caution when using DSIs is to carefully choose whether to represent the average rate of association as the mean or median. As noted in Ostner \& Schulke (2018), rates of interaction are typically right-skewed and are likely to be more so among individuals in large vs. small social groups. Using a population median in multi-group studies could prevent group-size effects, such as large groups lowering the population's mean dyadic rate of interaction, which inflates DSIs in small groups (e.g., Thompson \& Cords, 2018).

One way to characterize the bondedness of an individual is to average or sum the strength of its ties that are 'strong' or with 'close' partners, where strong and close are determined by some threshold. Some authors have chosen a priori an individual's top 2-3 partners, ranked by tie strength, to represent its close partners (Schülke et al., 2010; Silk et al., 2010b; Massen \& Sterck, 2013; Thompson \& Cords, 2018). This number may indeed be biologically relevant as group-living mammals appear to affiliate with decreasing intensity among tiers of social partners that increase in size by multiples of 3, starting with the self (Zhou et al., 2005; Hill et al., 2008). Other studies have designated strong ties as those with a DSI > 1, i.e., greater than the group mean or median DSI (McFarland et al., 2017), or those with dyadic association indices greater than chance (Mitani, 2009).

A second important aspect of dyadic bondedness is tie stability over time, which has been measured in several ways. The predictability of a tie can be measured by its coefficient of variation measured across different time points (Duboscq et al., 2017), the probability that a dyad will be observed associating at a given time lag from their previous association (Henzi et al., 2009), or whether the tie's ranked strength among an individual's ties predicts its ranked strength at a later time (Gilby \& Wrangham, 2008; Langergraber et al., 2009; Mitani, 2009). The stability of a tie can also be characterized by whether the social partner remains within the individual's 'close' partners over time (Silk et al., 2006, 2013; Thompson \& Cords, 2018). This same approach works on an individual level, too, by measuring the overall consistency of the identities of an individual's close partners over time (Silk et al., 2009, 2013; Thompson \& Cords, 2018).

A final aspect of dyadic bondedness is tie symmetry. Two popular measures of symmetry are the equitability of reciprocal exchange in grooming 
behaviour (e.g., Duboscq et al., 2017) and bias in responsibility for maintaining spatial proximity (i.e., the Hinde index, Silk et al., 2013). Symmetry is useful to indicate how each partner values the other, e.g., a highly asymmetric tie may mean partner A is more valuable to B than vice versa (Fraser $\&$ Bugnyar, 2010). Symmetry may also be relevant to characterize the predictability and stability of a tie, as the timing of any reciprocated behaviour is less certain in asymmetrical ties. Measures of symmetry are potentially sensitive to the time period over which reciprocal exchanges are measured: for instance, the exchange of grooming behaviour in chimpanzees is more symmetric when measured over longer periods (Gomes et al., 2009). As tie symmetry measures the exchange of the same kind of behaviour, it is not directly relevant to interchange, or the exchange of different kinds of affiliative behaviour. Therefore, like other social measures, alone it does not necessarily capture an individual's full return on social investment such as the receipt of coalitionary support in exchange for affiliative behaviour.

Integration is frequently measured as one's diversity of partners. Simple measures of individual partner diversity include number of different social partners (equivalent to social network degree) and number of different social roles. Differing social roles are often characterized in the human literature to include 'spouse', 'parent', 'member of a religious group', etc. (Uchino, 2004; Holt-Lunstad et al., 2010). In humans, such roles are thought provide individuals with a sense of identity that is accompanied by a social obligation and incentive to remain healthy (Uchino, 2004). Though such roles are difficult to apply in many non-human animals, heterogeneity (e.g., coefficient of variation) in tie strengths themselves could provide a similar metric, where greater heterogeneity could indicate a diversity of social roles (Henzi et al., 2009). A somewhat more complex measure of partner diversity, which was adopted from community ecology has not been associated with fitness outcomes, is the Shannon Weiner Diversity Index (SWDI) (Smith \& Wilson, 1996). This measures both the amount of time an individual spends affiliating and how evenly it spreads affiliation among potential partners (Silk et al., 2013). In social contexts, individual SWDI is perhaps most meaningful when expressed relative to its maximum possible SWDI, in what has been called the diversity ratio (Cheney, 1992). Care should be taken when implementing the SWDI or the diversity ratio, as they are biased by any uneven sampling among individuals, e.g., SWDI is likely higher the more an individual is sampled (Di Bitetti, 2000; Silk et al., 2013). Diversity ratio can also 
be easily biased by varying group sizes in multi-group studies, as maximum SWDI is inherently smaller in larger vs. smaller social groups.

Additionally, integration can be measured by an individual's position within a social network using social network analysis (SNA, Hanneman \& Riddle, 2005; Brent, 2015). Measures of an individual's position within a social network are centrality and local clustering coefficient, which is also known as local transitivity (Brent, 2015; Cheney et al., 2016). There are several ways of expressing centrality, including eigenvector centrality, betweenness, and measures of closeness, including reach and power (Table 1). Although centrality measures correlate with fitness outcomes in several instances (Brent, 2015; Ostner \& Schülke, 2018), there are not yet any similar correlations between clustering coefficient and fitness. Measures of centrality are generally considered to be useful measures of one's access to and ability to disseminate information, influence, and possibly disease (Brent, 2015). Whereas local clustering coefficient, which refers to the connectedness of one's social partners with one another, is perhaps more indicative of the 'texture' one's regular social life (Hanneman \& Riddle, 2005). For example, an individual with a high clustering coefficient may associate simultaneously a given set of partners, possibly facilitating cooperation or tolerant co-feeding between more than two individuals (Brent, 2015). When building a network, important decisions include choosing the type of association index used to construct the ties (edges) between individuals in a network (nodes), determining sufficient sampling effort or time over which data should be collated, and choosing how to treat potentially missing observations (Farine \& Whitehead, 2015; Davis et al., 2018; Hoppitt \& Farine, 2018).

\subsection{Controlling for non-social third variables in measuring ties}

To quantify ties, one should attempt to control for spatial preferences that are driven by non-social factors. This may be particularly relevant for fissionfusion societies where individuals are often members of sub-parties for the entire day, which limits their opportunities for interaction to those individuals that chose to travel to the same areas within a home range. Controlling for space-use within association indices can be done by calculating spatial association according to the proportion of observations in which either individual were present in the same subgroup, e.g., a pairwise affinity index or half weight index (Mitani, 2009; Mann et al., 2012; Best et al., 2014). These indices also effectively control for generally gregarious personalities, or an 
individual's general preference to join sub-parties, and so reveal preferences for particular partners. In species where individuals maintain unique home ranges, one can test the efficacy of these measures for controlling for spatial preferences by, e.g., modelling the influence of home range overlap on association indices (Langergraber et al., 2009; Best et al., 2014; Foerster et al., 2015). Also, in an experimental setting, one can manipulate available spaces and see if preferences for association hold (e.g., Durrell et al., 2004). Domestic pigs, for example, prefer particular resting areas within their sties, but not the company of particular sty-mates (Durrell et al., 2004). After the structure of the sty was changed, individuals did not prefer to associate spatially with their previous partners.

Several other factors, apart from space use, can cause pronounced fluctuations in tie strength, such as seasonal availability of food, mates, or the presence of infants (Henzi et al., 2009; Brent et al., 2012; Foerster et al., 2015), life history state including development and senescence (Berman, 1982; Almeling et al., 2016), extraordinary climatic or demographic events (Sapolsky, 1986), predation or infanticide (Engh et al., 2006b; Wittig et al., 2008) and group fissioning (Cords, 2012). To assess the stability of ties despite these factors, behavioural data can be collated over periods that represent either stable environments, such as mating and non-mating seasons (Schülke et al., 2010), or simply cover all seasons in a year for all individuals (Thompson \& Cords, 2018). One can also control for variation in the environment by clustering observations by habitat type (Silk et al., 2003), by creating indices specific to a given context of interaction (e.g., food vs. non-food; Smith et al., 2010), or including an index of environmental quality (e.g., fruit availability) as analytical controls. Finally, observations potentially influenced by third variables could be omitted altogether. For example, in calculating a dyadic composite sociality index in female baboons, Silk et al. (2009) removed interactions when either female had an infant under 100 days old.

\subsection{Impact of early life experience on social ties and fitness: controlling for an unexplored confound}

A potentially important third variable that is often overlooked in studies of social influences on fitness is early life experience, including motheroffspring relationships and early environmental conditions, such as food availability and population density. Such early life parental and physical experiences can influence individual sociality in a number of ways, including 
future parental behaviour (Margulis et al., 2005; Champagne et al., 2006; Maestripieri et al., 2006; Champagne, 2008; Kappeler \& Meaney, 2010), affiliative tendencies and partner preferences (Uchino, 2009; Hawkley et al., 2012; Branchi et al., 2013; Feldman et al., 2013; Ilany \& Akçay, 2016; Tung et al., 2016; Jarrett et al., 2018), aggressive tendencies and dominance behaviour (Bastian et al., 2002; Sachser et al., 2011) and emotional regulation (Weaver \& de Waal, 2003; Weaver et al., 2004; Allen et al., 2007; Branchi et al., 2009; Clay \& de Waal, 2013). Early life experience can also influence survival (Tung et al., 2016; Alberts, 2018), reproductive success (Altmann, 1991; Margulis et al., 2005; Douhard et al., 2014), and risk of particular disease (Delpierre et al., 2016). This leads to the clear possibility that early life conditions influence both sociality and fitness simultaneously, and potentially drive a spurious correlation between them in adults. As such, examining the influence of early life conditions on adult ties and fitness and including them in explanatory models relating ties and fitness are advisable whenever possible.

Factors that seem to be particularly likely to influence sociality and fitness simultaneously are those that represent variation in both parental care and access to nutrition, such as early maternal loss, number and age-spacing of siblings (e.g., Tung et al., 2016), and potentially maternal dominance rank. Although studies that find correlations between ties and fitness typically control for adult dominance rank (or socio-economic status in humans; reviewed in Uchino, 2004), early life maternal rank can differ from individual rank in adulthood. Other variables that could potentially serve as controls for the latent influence of early life conditions are life history traits that indicate an individuals' so-called pace of life: growth rate, age at first reproduction, and inter-birth interval. Pace of life is closely related to individuals' risk-taking and exploratory behaviour, reproductive output, and their survival, and it is often canalized via early life experience (Wolf et al., 2007; Biro \& Stamps, 2008, 2010; Réale et al., 2010).

\section{Pathways by which social ties influence fitness}

Several studies present evidence that high gregariousness, many ties, or strong and consistent ties correspond with better fitness-related outcomes (also see Table 1 in Ostner \& Schülke, 2018). The seminal work of Silk and colleagues on two populations of savannah baboons brought the question 
'do social ties matter?' to the fore (Silk et al., 2003, 2009, 2010b) and in the following decade, several studies have examined links between either the quality or quantity of social ties and fitness outcomes, such as longevity (Yee et al., 2008; Barocas et al., 2011; Foster et al., 2012; Stanton \& Mann, 2012; Archie et al., 2014; Vander Wal et al., 2014; Yang et al., 2016; Brent et al., 2017; Thompson \& Cords, 2018), survival during or after a traumatic event (McFarland \& Majolo, 2013; Nuñez et al., 2015; Lehmann et al., 2016), reproductive output (Weidt et al., 2008; Schülke et al., 2010; Brent et al., 2013; Gilby et al., 2013; Wey et al., 2013; Vander Wal et al., 2014; McFarland et al., 2017) and infant survival (Cameron et al., 2009; Frère et al., 2010; Cheney et al., 2016; Kalbitzer et al., 2017; McFarland et al., 2017).

My goal is not to synthesize the findings of the above studies, but rather to highlight that they provide only one kind of evidence of that ties influence fitness: variation in social strategies correlates with variation in fitness outcomes. Of the studies listed above, the only ones that present evidence suggestive of a pathway by which ties benefit individuals are Cameron et al. (2009), Stanton et al. (2012) (avoiding harassment), McFarland \& Majolo (2013) (thermoregulation) and Schulke \& Ostner (2010) (rank acquisition). Understandably, single studies rarely present both outcomes and the pathways by which they arise, because short-term projects are frequently unable to measure outcomes and long-term projects do not have the data to test pathways in hindsight.

Currently, our best guesses at how social ties influence fitness are the ways that they seem to benefit individuals in the short-term. Admittedly, this approach involves drawing many course-grained relationships. As Grafen (1984) said, behavioural ecologists typically use a 'phenotypic gambit.' Instead of describing the genetic basis of a behavioural trait and the change in its gene frequency over time within a population, one measures a trait phenotypically, assumes a very simple genetic structure underlies it, and evaluates the trait's association with particular pay-offs, which ideally are fitness outcomes. In field studies on long-lived animals, pay-offs are most likely to be short-term benefits, and evidence that links short-term benefits to fitness outcomes, if available, exists in a separate study (Silk, 2007).

In the following paragraphs, I review such short-term benefits as 6 nonmutually exclusive pathways by which ties influence fitness (Figure 1). The relevance of any given pathway is dependent on the natural history and social organization of a given species, and the sex and age of a given individual. 
Importantly, the evidence of links along each of these pathways from social ties to individual fitness is not equally strong. Two kinds of evidence are required to demonstrate pathways as present in a given species: (1) a link between the affiliative or cooperate tie and the immediate benefit (e.g., ties $\rightarrow$ better communal care of offspring) and (2) a link between variation in benefits and fitness outcomes (e.g., better communal care $\rightarrow$ increased reproductive success). One can therefore think of a pathway as a sequence of mechanisms, or links, between ties and fitness outcomes. As shown in Figure 1 by solid lines, strong evidence for links exists along certain pathways in at least some species, e.g., establish, conserve and increase social power. Other pathways, such as developing social competence, are promising, but require further testing to directly link ties to short-term benefits and benefits with fitness outcomes. Ideally, studies could present evidence for each of these links within the same set of individuals to explain correlations between their social ties and fitness outcomes (e.g., Schülke et al., 2010).

\subsection{Pathway 1: communal care of offspring and allomothering}

Rearing offspring is a formidable cost for individuals to bear, which some primate species successfully alleviate through communal care (Lewis \& Pusey, 1997). Care from non-mothers, i.e., allomaternal care, can benefit both mother and carer: mothers increase foraging time and reduce carry time (Stanford, 1992) meanwhile carers, i.e., often young females, can gain mothering experience that can help their own future offsprings' survival (Fairbanks, 1990; Ross \& MacLarnon, 2000; Pillay \& Rymer, 2015). Nevertheless, allomothering can be costly to mothers, as some females can abuse infants or refuse to return them to mothers. This is particularly likely to occur in species where females form steep and despotic dominance hierarchies (Schino et al., 1993; Maestripieri, 1999; Ross \& MacLarnon, 2000). Indeed, Ross \& MacLarnon (2000) hypothesized that female-female competition limits the occurrence of allomaternal care across species. As the value of social ties in the context of communal care is not well studied in primates, I propose that competition could also limit allomothering within a social group or community, in species where allomothering does occur. Social ties could effectively help individuals circumvent potential abuses related to mother and allomother's power differentials. One might test the prediction that higher quality ties between mothers and potential caregivers results in higher frequency and quality of allomaternal care, and related benefits to mother and caregiver. 
In some non-primate species, chosen social partners are key in helping care for offspring exactly because the partner poses little risk to mother or offspring (e.g., house mice and eider ducks, Öst et al., 2003; Weidt et al., 2008, 2014). Among house mice, for instance, adult females that were experimentally allowed to form communal nests with preferred spatial associates engaged in less overt aggression and enjoyed higher average individual reproductive success (number of offspring successfully weaned) than females paired with non-preferred partners (Weidt et al., 2008). Further, mouse pups raised communally vs. only by their own mother show enhanced behavioural development (Curley \& Branchi, 2012), faster growth, greater survival, and greater lifetime reproductive success among females (Weidt et al., 2014). Weidt et al. (2014) found that female mice were more likely to form communal nests when more partners were available, however less likely if population density was high, suggesting that females are not demographically obligated to rear communally but indeed choose it as a strategy given a suitable partner.

\subsection{Pathway 2: group level cooperation to acquire resources}

In species that cooperatively hunt and/or defend territory, the following pathways are unlikely to yield within-group inter-individual differences in fitness, as many or all group members participate in the activities and share its success. Testing whether social ties lead to increased fitness via these types of behaviour most likely requires between group comparisons, as in Barocas et al. (2011).

\subsubsection{Cooperative hunting}

Maintaining strong and/or diverse ties in the context of cooperative hunting may increase hunting success and optimize individual foraging efficiency (Bailey et al., 2013; Ruch et al., 2014). In theory, individuals hunt cooperatively when their average individual energy intake is higher when hunting as a group than when hunting alone (Bailey et al., 2013; Ruch et al., 2014). It occurs in a wide range of taxa including carnivores, cetaceans, primates, birds, and social spiders, in which the dependence on hunting as a source of food varies widely (Bailey et al., 2013). Currently, there is little evidence to suggest that variation in the quality of ties among hunters corresponds with the efficiency of hunting. A study in spiders, however, suggests that hunting in family units vs. similarly-sized yet unrelated groups increases hunting efficiency (Ruch et al., 2014). Indeed, species that hunt cooperatively usually 
do so in extended family units, suggesting that familiarity, predictability, and tolerance may play a role in facilitating cooperation during the hunt (Bailey et al., 2013). In chimpanzees (Melis et al., 2006) and hyenas (Drea \& Carter, 2009), tolerance also appears to facilitate coordination on experimental tasks that mimic foraging and hunting.

Cooperative hunting occurs among only two non-human primates, chimpanzees and bonobos, and in each, hunting is rare and prey is not a major component of the overall diet (Watts \& Mitani, 2002; Surbeck \& Hohmann, 2008). Variable success in hunting is, therefore, perhaps unlikely to strongly impact individual fitness in these species, though cooperative hunting and foraging are thought to have played a central role in human evolution (Hill, 2002). In any case, future studies on any social hunting species could test whether variation in ties among hunters corresponds with their hunting success. Tie measures to test include the average DSI among participants based on their non-hunting associations, measures of the connectivity of the participants' non-hunting affiliative network (e.g., global network degree, global clustering coefficient), and even the average number of times participants have hunted with each other (i.e., familiarity in the context of hunting alone). Differential success in cooperative hunting could, alternatively, result from individual hunter experience and expertise, hunter age, number of hunters in the party, aspects of the prey (e.g., its group size and individual age and body size), and features of the ecological environment (e.g., visibility, continuity of canopy), rather than the quality of ties among hunters (Fanshawe \& Fitzgibbon, 1993; Creel \& Creel, 1995; Krause \& Godin, 1995; Holekamp et al., 1997; Boesch, 2002; Watts \& Mitani, 2002; Sand et al., 2006; Gilby et al., 2015). As such, controlling for these confounds would be important in testing for the role that ties play in hunting success.

\subsubsection{Cooperative defence of feeding territory}

Alliances to cooperatively defend feeding territory often increase territory quality (Peres, 1989; Mosser \& Packer, 2009), which is likely to increase its inhabitants' fitness (Emery Thompson et al., 2007; Crofoot \& Wrangham, 2010). Even among males, in chimpanzees, territorial alliances appear to increase males' reproductive success by enhancing the fertility of coresident females (Williams et al., 2004). Group territorial defense occurs widely among primates (Mitani \& Rodman, 1979), and its benefits form a core of the evolutionary theory of primate group-living (Koenig, 2002). 
However, as in cooperative hunting, the influence of the quality of particular ties on the efficiency of cooperative territorial defence is largely unknown.

The benefits of effective territorial defence have been proposed to select for group cohesion and team-building social behaviour such as increased tolerance (de Waal, 1986; Sterck et al., 1997; Koenig, 2002) and more diverse and reciprocal grooming among group members (Cords, 2002; Majolo et al., 2016). These proposals have received partial and sometimes conflicting evidence. In red howler monkeys, groups of females enjoy higher reproductive success when members of cooperative territorial alliances were related vs. unrelated, and were thus perhaps more tolerant of one another (Pope, 2000). Majolo et al. (2016) found across 15 species of primates that frequency of intergroup conflicts corresponded with females having more grooming partners, or higher network degree. Nevertheless, in vervets alone, Cheney (1992) found that average grooming diversity ratio across females did not increase with either frequency or success in inter-group conflicts, as expected. Among these studies, only Cheney (1992) tested the relationship between group member relationship quality and conflict outcome specifically, a profitable focus for future studies.

Although data on individual participation in inter-group conflicts is often difficult to gather, further studies might focus on examining how social ties among defenders alone, vs. all group members, corresponds with successful defence. Additionally, outcomes of territorial behaviour may be difficult to categorize as simple wins and losses. For example, male chimpanzees are more likely participate in boundary patrols with social partners with whom they share a stronger tie (Watts \& Mitani, 2001), but patrols do not always result in a direct conflict with neighbours. When conflict outcomes are clear, simple measures of individual integration like average group member degree, or global network density as in Majolo et al. (2016), might positively predict outcome. Relevant social variables to test are the same as those that perhaps influence success in cooperative hunting, listed above. Important alternative variables that frequently drive variation in successful territorial defence are number of defenders, time invested in defence and the location of the between-group conflict relative to the centres of either social group's home range; therefore, controlling for these effects is necessary (Peres, 1989; Radford \& du Plessis, 2004; Mosser \& Packer, 2009; Wilson et al., 2012; Roth \& Cords, 2016). 


\subsection{Pathway 3: monopolizing resources within social units}

Males in many group-living species use long-term cooperative alliances to access and monopolize mates. The adaptive benefit of mate-guarding alliances is that individuals achieve more copulations on average when in an alliance than when alone (Whitehead \& Connor, 2005). A classic example of mate-guarding alliances occurs in bottlenose dolphins (Connor et al., 2001; Whitehead \& Connor, 2005; Connor, 2007; Wiszniewski et al., 2012a; Bruck, 2013), in which affiliative, non-kin partners form long-term cooperative alliances (up to 20 yrs, Connor et al., 2001). Males in stable alliances had higher rates of consorts than males in more transient alliances (Connor et al., 2001), suggesting a clear benefit of maintaining particular alliance partners. The tendency to form such alliances often varies by population, revealing the circumstances in which cooperation is most likely to pay off: males are more likely to form alliances if smaller bodied, relative competitive abilities of alliance members are more similar, and the operational sex ratio of communities is male-biased (Whitehead \& Connor, 2005). Males may also benefit from forming alliances by increasing access to females via mate choice. Females appear to prefer to mate with males in larger alliances (Wiszniewski et al., 2012b) or who have more synchronous displays, perhaps because size and synchrony signal male competitive ability (Connor et al., 2006).

Mate-guarding alliances also occur in several primate species. A pattern of mutual gain is apparent in mate-guarding alliances of male chimpanzees in which dominant and subordinate partners tolerate the other's consortships in turn (Watts, 1998). In baboons, allied males do not appear to share a longterm affiliative tie, but they do appear to selectively choose their alliance partners, possibly based on preferences formed from previous interactions (Noë \& Sluijter, 1995). As in dolphins, the pay offs of mate guarding alliances among male primates maybe situational: middle, but not low-ranking, male baboons in both Amboseli and Gilgil are more likely to form mate-guarding alliances, which steal females from consortships with higher-ranking males (Noë \& Sluijter, 1995). To accurately assess the influence of an individual's cooperative mate-guarding behaviour on its fitness, one must also examine and control for variables that predict the likelihood of cooperatively mateguarding, as these importantly represent the strength of male competition and female choice in a given species-population. Some of these variables include male dominance rank (discussed further below), male age, number 
of males and females, synchronicity of female oestrus, and degree of sexual dimorphism (Cowlishaw \& Dunbar, 1991).

Unlike males, female primates frequently form within-group alliances to monopolize food and nest sites. Similar to the conditional pay-offs of male mate-guarding alliances, the formation of differentiated ties and competitive alliances among females appears to depend on the monopolisability of the resource defended, i.e., whether it is discrete, easily guarded, and/or easily consumed (Sterck et al., 1997; Isbell \& Young, 2002). A comparison of two subspecies of squirrel monkey demonstrates this principle. In the subspecies whose foods were monopolisable, females formed friendships and competitive alliances (Mitchell et al., 1991). In the subspecies whose food was not monopolisable, female ties were undifferentiated. Comparisons between subspecies and populations are useful to understand the circumstances in which cooperation is beneficial. However, a direct link between social ties and fitness via cooperative alliances for food requires analyses of inter-female variation in cooperative behaviour and fitness outcomes. Such analyses require controls for the likely pervasive influence of social power, or dominance rank, on reproductive success and survival. Social power, itself, may result from cooperative alliances and is addressed further in the following section.

\subsection{Pathway 4: establishing, maintaining, and increasing social status}

In many cases, competitive alliances do not aim to secure access to resources directly, but rather to secure social power and standing within a dominance hierarchy, which often translates into the priority of access to resources that might not be present at the time of conflict. Among adult males dominance rank often translates to priority of access to mates, and among females and juveniles rank often translates to priority of access to food, space, and nesting sites (Clutton-Brock \& Huchard, 2013). Consequently, social status has clear ties to fitness in several species. In a meta-analysis of several cercopithecine primates, male dominance rank accounted for $50 \%$ of the variance in mating success (Altmann \& Alberts, 2003; Alberts, 2012), typically decreasing in explanatory power with increased male-male competition for females (Cowlishaw \& Dunbar, 1991). Among females of several species, too, high rank corresponds to shorter inter-birth intervals, earlier ages at reproductive maturity (Holekamp et al., 1996; Pusey et al., 1997; Altmann \& Alberts, 2003; Pusey, 2012), and faster infant growth (Altmann \& Alberts, 2005). 
During development, ties are highly valuable for establishing social power in species that form dominance hierarchies, particularly for individuals of the philopatric sex. Juveniles typically form alliances with older allies such as mothers or maternal kin (Chapais \& Gauthier, 2004), to establish their optimal dominance status. In some species, this status is that just below their mother's: maternal support in conflicts often causes juvenile females to dominate all females that their mother dominates, and to 'inherit' that rank for life (Horrocks \& Hunte, 1983; Engh et al., 2000). For males too in some species, such as bonobos, dominance rank increases with higher maternal rank and male rank declines when mothers are no longer present in the community (Surbeck et al., 2011), suggesting that alliances with mothers are necessary for males to conserve their status. Although males' rank postdispersal is not necessarily equal to their rank pre-dispersal (e.g., Smale et al., 1993), the nutritional and social advantages of high rank in one's natal group could cause a male to disperse sooner rather than later and to groups offering optimal mating conditions, thereby potentially extending a male's reproductive career (e.g., Höner et al., 2010).

In adulthood, too, alliances can be important for both maintaining and increasing social status. In general, the occurrence of coalitions maintain or increase rank are relatively rare among philopatric adult females, perhaps because single events are salient enough to reinforce developmentally established dominance relationships (Smith et al., 2010). As such, among individuals of a philopatric sex, ties during development may be more influential for increasing fitness via dominance rank. Nevertheless, adult philopatric females do maintain alliances that typically conserve their position within a dominance hierarchy (Smith et al., 2010). Without conservative coalitions, adult females may succumb to revolutionary coalitions. For example, in a group of Japanese macaques where few individuals were closely related, adult females came to be outranked by juveniles of subordinate mothers, because these juveniles opportunistically joined bridging coalitions with higher-ranking females (Chapais \& Gauthier, 2004). Also in Japanese macaques, when a female's kin were experimentally removed from a group, she succumbed to revolutionary coalitions and rapidly fell in dominance rank, but she was able to regain her former rank upon the reintroduction of her kin (Chapais, 1995).

The use of alliances to increase social power among males of femalephilopatric species is perhaps one of the best-evidenced pathways connecting 
social ties to increased fitness. Assamese macaque males maintain affiliative ties with coalitionary allies and those with stronger ties with their top three affiliative partners were also more likely to rise in rank and sire more offspring in subsequent periods of observation (Schülke et al., 2010). Schülke et al. (2010) effectively demonstrated that stronger affiliative ties between males led to coalition formation, coalition formation increased individual rank, and increases in rank led to increased reproductive success. Such phenomena may also occur among males in the several other primate species wherein males use alliances to vie for top rank (Chapais, 1995). For example, male chimpanzees form long-term, equitable ties with each other (Mitani, 2009), which often correlate with cooperative alliances (for rank, territorial defense, and meat sharing, Mitani et al., 2000). Still, evidence for the reproductive benefits of affiliative and cooperative ties do not appear to be as straightforward in male chimpanzees as in male Assamese macaques. For example, rank-related coalitionary behaviour alone, even preceding increases in rank, corresponds with high reproductive success among males in one chimpanzee population (Gilby et al., 2013). This perhaps occurs because frequently supported males, e.g., alphas, exchange social tolerance for coalitionary support, allowing lower-ranking males that support them to have access to mates (Duffy et al., 2007). The relationships between affiliation, cooperation, rank, tolerance and reproductive success among male chimpanzees provides a good example of how pathways leading from ties to fitness are not mutually exclusive. The increase of social tolerance is addressed further under pathway 5 , which discusses how ties lower social and environmental risks.

\subsection{Pathway 5: reducing exposure to risk and allostatic load}

In most animals, both behaviour and endocrinological mediators help individuals to avoid risks and to maintain homeostasis (Romero et al., 2009; Schulkin, 2011; Edes \& Crews, 2017), which are centrally important for fitness in all organisms. As such, reducing exposure to risk, in its several forms, may constitute one of the most important pathways proposed in this review. In the human medical and psychological literature, social ties that serve this function are collectively referred to as 'social support' (Uchino, 2009; Gunnar, 2017), and typically partitioned into 'instrumental' and 'buffering' support. The former describes support that decreases or removes the risk or energetic challenge in the environment, such as sheltering individuals from 
harassment, predators, and extreme cold. The second refers to support that either reduces the psychological perception of risk and/or helps individuals return to homeostasis following their response to a challenge (i.e., their stress response). Reducing the psychological perception of risk is, of course, only a benefit if the risk is no longer present in the environment. Humans and laboratory animals, for example, are rarely more likely to be exposed to a predator when alone, but still increase sympathetic activity and vigilance when alone (Hawkley \& Cacioppo, 2010).

Given the differences in instrumental and buffering support, the following specific sub-pathways of avoiding risk and alleviating allostatic load can be evaluated in two ways. One can test whether gregariousness, bondedness, or integration corresponds with decreases in exposure to the actual stressor itself, and/or whether they correspond with decreases in the subjective experience of the stressor. Evidence of such experience is, however, more difficult to gather in non-human animals than humans.

Monitoring sympathetic activity and important endocrinological mediators of homeostasis following a potential challenge is one way to gauge both an individual's experience of risk and their deviation from homeostasis, or allostatic load. Allostatic load can be measured across several physiological systems, e.g., cardiovascular and immune, however it is most commonly measured in wild animals by one of its primary mediators, glucocorticoid hormones (GCs; Edes \& Crews, 2017). GCs catabolize glycogen into readily available glucose to respond to current and anticipated energetic needs, and dampen the activity of other physical processes that are less immediately important for survival, such as inflammatory immune responses and reproduction (Sapolsky et al., 2000). Although long-term elevations in GCs are often characterized as maladaptive, as they can damage their own negative feedback mechanism, individuals' long-term memory and fertility (Sapolsky et al., 2000; Sapolsky, 2005), and increase inflammatory immune profiles (Snyder-Mackler et al., 2016), it is still unclear how relevant consistently elevated GC levels are to the fitness of wild animals (Bonier et al., 2009; Beehner \& Bergman, 2017). In any case, variation in baseline GCs between individuals, and deviation from baseline within individuals, are often useful signals of the challenges that an individual or population of individuals experiences (Beehner \& Bergman, 2017).

A strong alternative hypothesis is that social ties actually increase exposure to certain risks and increase allostatic load, as the possibility of aggression and injury is only possible when in proximity to social partners and 
disease transmission is much more likely (Hamede et al., 2009; Vander Wal et al., 2012; Kappeler et al., 2015; Friant et al., 2016; Yang et al., 2016; Kalbitzer et al., 2017; Thompson et al., 2019). In light of this alternative, another useful hypothesis to evaluate is that long-term benefits of social ties outweigh some immediate costs. For example, in Japanese macaques, juvenile females were at increased risk of harassment when first grooming adult females, but with time developed tolerant relationships with the same adults (Schino \& Alessandrini, 2015). Similarly, juvenile blue monkeys experience the higher glucocorticoid levels when they spend more time grooming with non-kin vs. kin group members, who could be useful allies later in life for females (Thompson et al., 2019). Therefore, the initial cost of affiliative interactions could be outweighed by a later benefit, such as increased access to resources via competitive alliances and/or tolerance in co-feeding or sharing of predator-safe microhabitats. Long-term data will be particularly valuable in evaluating this alternative.

\subsubsection{Protection from harassment}

Living in social groups increases direct and indirect competition for resources, making spatial association and social interaction a risk factor for aggression, harassment, and consequent injury (e.g., Schino \& Alessandrini, 2015; Kalbitzer et al., 2017). Nevertheless, building affiliative and cooperative ties can provide instrumental support to reduce these risks. One mechanism of risk reduction is the interchange of affiliation for tolerance (Barrett \& Henzi, 2006; Duffy et al., 2007; Madden \& Clutton-Brock, 2009; Kutsukake \& Clutton-Brock, 2010; Haunhorst et al., 2017). In Assamese macaques, females suffer less harassment from a male the stronger her affiliative tie is with him (Haunhorst et al., 2017). It is also proposed that higher-ranking individuals receive more social grooming than they give, because lower status individuals are essentially paying for their tolerance (Seyfarth, 1977; Kutsukake \& Clutton-Brock, 2010).

Additionally, social ties can physically shield individuals from harassment, via coalitions and interventions. This is particularly relevant for females to evade male sexual aggression (Smuts \& Smuts, 1993; Palombit et al., 1997; van Schaik et al., 2004). For example, female langurs frequently form coalitions to defend one another from the harassment of potentially infanticidal males (Sterck et al., 1997), though whether the quality of female social ties relates to the likelihood of coalition formation is not known. In feral horses, mothers that were more sociable with female peers (high CSI) 
received less harassment from adult males, likely leading to the higher survival of their foals (Cameron et al., 2009). Active protection from infanticidal males also appears to be the primary benefit of so-called 'friendships' between male and female savannah baboons (Palombit et al., 1997; Palombit, 2009). Juvenile male dolphins were also suggested to avoid harassment from older juveniles by being more socially integrated (eigenvector centrality) (eigenvector centrality, Stanton \& Mann, 2012). Association with mothers, which are formidable allies, may be an important cause of this effect as males that associated more frequently with their mothers had higher eigenvector centrality. Again, as an important alternative, social integration can also increase individuals' risk of harassment particularly if being socially central equates to being spatially central to the group, as seen in female capuchin monkeys (Kalbitzer et al., 2017).

\subsubsection{Protection from environmental variation and predation}

Social partners can also provide instrumental support in helping defend individuals from challenges in the physical environment, such as food scarcity, cold temperatures, and predation. As noted in the above section, affiliative ties often translate into tolerance in contexts where individuals naturally compete for limited resources, such as food or warmth. As such, individuals do not simply avoid social aggression, but also gain access to important natural resources and avoid non-social risks. For example, tolerant or preferential co-feeding increases with a stronger affiliative tie between partners in Assamese macaques (Haunhorst et al., 2017) and dairy cows (Val-Laillet et al., 2009). Similarly, the strength of a tie between female baboons in the Namibian savannah significantly predicted their likelihood to co-feed with one another, and did so more strongly than relatedness (King et al., 2011). Further, in white tufted capuchins, females clearly exchanged grooming for tolerance in co-feeding contexts (Tiddi et al., 2011).

Simply having more social ties may also increase the number of partners that tolerate bodily contact, enhancing thermoregulation in fluctuating climates. In South Africa, temperatures fall below freezing during winter, and vervets huddle together at night to help maintain homeothermy (McFarland et al., 2015). Vervets that had more spatial and/or grooming partners throughout the day maintained a higher minimum body temperature and varied less in temperature from day to night, as measured by a subcutaneous thermometer. Number of social ties appeared to translate, too, into thermal efficiency for male and female adult and subadult Barbary macaques in the 
Atlas Mountains, where individuals with more ties were more likely to survive an intense winter (McFarland \& Majolo, 2013; Lehmann et al., 2016). In both species, more social ties during the day perhaps allowed individuals to occupy key huddling locations among group members to stay warm at night.

Social ties and their corresponding tolerance and familiarity can also influence exposure to predators. In some primates, a lack of tolerance between dominant and subordinate females appears to cause the lowest-ranking females to be located on the periphery of the group, leaving them exposed to higher rates of predation (van Schaik \& Van Noordwijk, 1986; Ron et al., 1996; Kalbitzer et al., 2017). In reverse, being tolerated by a larger number of potential neighbours could increase spatial integration in a group and reduce exposure to predators. For example, eigenvector centrality in spatial association networks of adult bighorn ewes increases their survival, reproductive output, and infant survival (Vander Wal et al., 2014). Interestingly, rams do not incur these benefits of high eigenvector centrality, perhaps because they are at lower risk of being preyed upon (Vander Wal et al., 2015).

Stronger ties may also help individuals to avoid predators because the familiarity between partners increases the efficiency of communication. In crested macaques, for example, adult females follow partners' eye movements more frequently and more quickly when they share a stronger tie (Micheletta \& Waller, 2012). In dwarf mongooses, too, individuals respond more readily, for longer, and are more likely to approach a caller with whom they are strongly vs. weakly bonded when the caller emits a recruitment call to mob predatory snakes (Kern \& Radford, 2016). Even among social mites, pairs of larvae that are familiar with one another react more quickly than unfamiliar pairs to the larvae of a predatory mite (Strodl \& Schausberger, 2012). In each of these species, differentiated ties increase predator detection. Individuals are more responsive to close partners perhaps because the cues of such partners are more easily recognizable than weaker partners, such partners have proven themselves trustworthy in their signalling, and the physiological basis of their tie increases their behavioural synchrony (e.g., Arueti et al., 2013).

\subsubsection{Coping with trauma and instability}

Associating with social partners often appears to provide buffering support in helping individuals cope with traumatic events and aggression (Engh et al., 
2006b; Young et al., 2014a; Wittig et al., 2016). In female baboons, experiences of infanticide, losing a close partner to predation (Engh et al., 2006b), and large upsets in the male dominance hierarchy (Wittig et al., 2008) caused both an increase in individual GC levels and a change in grooming patterns. Females who lost a close partner to predation increased the time they spent grooming and their number of grooming partners, in an apparent effort to compensate for their loss (Engh et al., 2006b). Females also responded to instability in the male dominance hierarchy by focusing, or decreasing the diversity of, their grooming ties to a smaller subset of individuals (Wittig et al., 2008). The decline in GC concentrations following hierarchical stability was more rapid the more intensely females focused their grooming associates, presumably to their closest social partners. Among these females, individual rates of grooming did not change from before to after the onset of instability, so it appears that changing the number of their grooming partners alone provided females with a sense of stability.

Alternatively, it is possible that simply associating regularly with a social partner attenuates HPA reactivity, leading individuals with regular partners to have lower baseline GC levels. Females baboons that maintained grooming networks that were more focused had lower baseline GC levels than females with less focused networks, even during periods of rank stability (Crockford et al., 2008). Indeed, chimpanzees that groomed with a strong vs. weakly bonded partner for a single bout, regardless of bout length or quality, demonstrated a drop in urinary GC levels relative to before grooming, both after a challenging event (intergroup encounter) and in the absence of challenges (Wittig et al., 2016). Affiliative contact may mediate HPA responses by stimulating the release of oxytocin (OT, Crockford et al., 2013; Seyfarth \& Cheney, 2013; Wittig et al., 2016), which can counteract the effects of GCs and reduce GC levels (Curley, 2011; Crockford et al., 2013).

The most supportive and stabilizing social strategy may depend on the particular stressors an individual faces given its condition. For example, following the immigration of a new male baboon, elevation in GC levels was highest among lactating females, the demographic group at greatest risk of infanticide (Engh et al., 2006a). Accordingly, more grooming partners were more likely to benefit lactating vs. non-lactating females. This conditiondependence may underlie variation in the social strategies that lower individual baseline GCs. For example, in rhesus macaques, females that had more ties, and partners with more ties themselves (i.e., proximity reach), 
had lower GC levels if they were low-ranking (Brent et al., 2011). In contrast, high-ranking females had lower GC levels when they were less socially integrated. In this case, however, it is not yet clear how dominance rank moderates the relationship between risk and social integration.

\subsubsection{Protection from isolation}

Social isolation appears to pose a physical threat to some social animals, particularly those that use social ties as defence against environmental risks, such as predators and extreme temperatures (Cacioppo \& Hawkley, 2003; Cheney \& Seyfarth, 2009; Hawkley \& Cacioppo, 2010; Cacioppo et al., 2011; Hawkley et al., 2012). The harm of social isolation is that the very motivation to reconnect with social partners, i.e., the sense of isolation, becomes physically costly when not satisfied or assuaged. In humans, the perception of isolation increases one's vigilance and expectation of an impending threat, which increases sympathetic activity (Hawkley \& Cacioppo, 2010). Prolonged rises in sympathetic activity can impact fitness by increasing peripheral resistance in blood vessels, hypertension, depression, risk of autoimmune disease, and myocardial infarction (Cacioppo et al., 2011). The presence of ties clearly decreases isolation, in another form of buffering support. Nevertheless, the damaging effects of isolation may only occur in extreme cases, such as among humans and in unnatural animal settings like zoos and laboratories (Beehner \& Bergman, 2017).

\subsection{Pathway 6: developing social and physical competence}

Maintaining ties during development appears integral to developing the socio-cognitive and motor skills that underlie success in adulthood. That is, ties during development seem necessary to develop behavioural competence, or the ability to assess stimuli and respond to it optimally (Pellis \& Pellis, 2007; Taborsky \& Oliveira, 2012). For this reason, social behaviour during development is often described as 'practicing for adulthood' (Coppinger \& Smith, 1989; Spinka et al., 2001; Fairbanks, 2003). I propose that the quality and quantity of social ties during development help individuals develop behavioural competence, via social learning and play, better preparing them for adult environments.

Evidence of links between the particular quality and quantity of ties during development (vs. mere presence of particular partners) and later life competence is strong in laboratory settings, but is rarer in wild and socially 
complex animals. Simultaneously, evidence is scarce on the specific link between competence and fitness. The difficulty of defining social competence in an observational field setting may be one cause of this shortage of evidence from the wild. In experimental laboratory settings, social competence is typically measured in terms of more or less optimal responses to competitive situations (Taborsky \& Oliveira, 2012). One possibly useful approach in field studies may be to measure social competence similarly to foraging and feeding proficiency (e.g., Bray et al., 2018), namely by observing the emergence of adult or age-typical behavioural repertoires or motor ability (e.g., Berghänel et al., 2015; Kaburu et al., 2016; Heintz et al., 2017). Another useful approach assessed socio-emotional competence in immature bonobos via individuals' speed of recovery from emotional distress (Clay \& de Waal, 2013). Naturally, what specifically constitutes 'competence' will vary according to age, sex, and the species in question.

\subsubsection{Social learning}

Maintaining particular individuals as regular social partners can be key to developing various important skills (Galef \& Laland, 2005; Evans \& Harris, 2008; Manassa \& McCormick, 2013; Kaburu et al., 2016), like foraging (Bshary et al., 2012; Farine et al., 2015; Bray et al., 2018) and independently navigating competition (Arnold \& Taborsky, 2010; Taborsky et al., 2012). The strongest evidence of ties helping to develop social skills comes from relatively short-lived animals whose social conditions are easily, experimentally manipulated (Pellis \& Pellis, 2007; Arnold \& Taborsky, 2010; Taborsky et al., 2012; Taborsky \& Oliveira, 2012). For instance, cichlids raised with (vs. without) older conspecific partners seem to learn socially appropriate behaviour by experiencing the varied social roles and competitive abilities of other individuals in their unit: those raised with older partners required fewer trials to respond appropriately (i.e., submissively) when experimentally introduced to a territory-holding individual (Arnold \& Taborsky, 2010). They also required fewer trials to develop proper aggressive responses to intruders when they were territory-holders, themselves. In terms of affiliative ties, such partners may be easier to observe and learn from: in captive ravens, the trained behaviour required to open a food box spread more readily between individuals that affiliated more often, and more readily between affiliative vs. antagonistic partners (Kulahci et al., 2016).

Social experiential diversity may also aid in developing social competence. Juvenile male long-tailed manakins that were more central within 
networks based on non-aggressive contact were more likely as adults to rise to alpha status within their leks (McDonald, 2007). Interestingly, the centrality of adult males did not predict rise to alpha status, suggesting that network centrality during development was key. McDonald (2007) argues that high juvenile centrality represents investment in several leks and that this leads to the development of proper dominant and submissive behaviour, which builds the social capital to gain high dominance status.

\subsubsection{Social play}

Ties that occur in the context of social play may serve a particularly important role in developing competence, as it provides opportunities for both social learning and physical maturation. Play predominantly occurs during immaturity and among peers, and is hypothesized to develop competence by providing 'practice for the unexpected' and 'self-assessment' (Spinka et al., 2001; Blumstein et al., 2013; Palagi, 2018). Social play consists of affiliative interactions that nevertheless involve acute social and physical challenges that are easily overcome and typically low risk. In this way, play allows individuals to gain cognitive and physical experience of unexpected situations and of their own abilities and limitations. In many cases, the higher frequency and quality of play during development correlate with important fitnessrelated traits, such as increased motor-skills (rats, Assamese macaques, and ground squirrels, Nunes et al., 2004; Bell et al., 2010; Berghänel et al., 2015; Schneider et al., 2016), appropriate submissive behaviour (rats, van den Berg et al., 1999; Pellis \& Pellis, 2007), higher dominance rank among adult males (marmots, Blumstein et al., 2013), increased territorial behaviour among adult females, and an increase in females' offspring's survival (ground squirrels, Nunes, 2014). In brown bears, play rates predicted cubs' survival of a subsequent, harsh winter, regardless of food availability (Fagen \& Fagen, 2004). The strongest evidence of the causal role of play in the above outcomes comes from experimental manipulations: immature rats deprived of play partners (but not other social partners) do not develop normal neural circuitry underlying socio-cognitive and motor skills (Pellis \& Pellis, 2007; Bell et al., 2010; Schneider et al., 2016).

Individuals show clear preferences for particular play partners, and so perhaps achieve better outcomes if able to play with them. Both male and female juveniles in several species prefer to play with partners that are similar to them in size and age, including several primates (Byers, 1980; Fairbanks, 
2003; Palagi et al., 2007; Barale et al., 2015) and non-primate species (Rothstein \& Griswold, 1991; Thompson, 1996; Nunes et al., 2004). Play with such partners may facilitate self-assessment. Alternatively, individuals may prefer more asymmetric pairings, perhaps to practice dominant and submissive behaviour, such as in domestic dogs (Ward et al., 2008).

\section{Summary and future directions}

The primary aim of this review is to facilitate future research on the influence of the quality and quantity of social ties on individual fitness in primates. Hypotheses concerning the effect of particular social measures along certain pathways can be tailored to the age-class and sex of individuals of a given species, in a given habitat.

In part 1 , I outlined the many ways of measuring individual social strategies and ties that can be relevant to fitness, including measures of individual gregariousness, bondedness, and integration. In particular, measures of social ties must be relevant to their suspected functions and the potential adaptive value of their partners through increased inclusive fitness, mutual gain, reciprocal exchange, or interchange. Controlling for third variables, such as ecological variation and mutual attraction to shared spaces and resources, and assessing time scales over which to characterize ties will lead to more valid measures of sociability and partner preferences. Examining and controlling for the influence of early life experience and individual pace-of-life on both the formation of ties and fitness, whenever possible, will help us to continue evaluating whether correlations between ties and fitness outcome are truly causal. To the same end, research can continue to examine how health status influences sociality and whether correlations between ties and fitness hold regardless of initial health status.

In part 2, the six pathways that ties can influence fitness included communal care, accessing resources at the group level; monopolizing resources within social units; establishing, maintaining, and increasing social status; reducing risk and allostatic load; and developing behavioural competence. As diagrammed in Figure 1, some of these pathways leading from ties to fitness have been more firmly established by evidence than others. For example, the influence of affiliative and coalitionary ties on fitness via maintaining and increasing social status is well-documented among male Assamese macaques (Schülke et al., 2010), however pathways such as communal care, 
accessing resources at a group level, and developing behavioural competence are in need of more direct evidence to support both the link between ties and their short-term benefits and the link between benefits and fitness outcomes. In the sense that these different kinds of evidence rarely occur within the same study subjects (e.g., Schülke et al., 2010), all pathways warrant further study and replication.

In summary, there are key and interrelated takeaways from each pathway. Allomothers can help alleviate the workload of infant rearing, and preferred partners may pose less risk of infant abuse and competition with mothers. Greater bondedness and integration among individuals participating in cooperative and collective activities, like hunting and territorial defence, may increase coordination and success in such activities. Suggestive evidence for ties influence in communal care exists in mice and ducks (Öst et al., 2008; Weidt et al., 2008, 2014), and for hunting success in social spiders (Ruch et al., 2014). Evidence for ties' influence on effective territorial defence does exist in primates; however, it is still only suggestive, relating to number of social partners and the occurrence of intergroup conflicts (Majolo et al., 2016) and number of kin groupmates to reproductive success in a highly territorial species (Pope, 2000).

The advantages of ties for monopolising mates or food is clear, among males and females, respectively; however advantages are strongly dependent on the competitive regime for the resource in question, such as the operational sex ratio (Cowlishaw \& Dunbar, 1991; Whitehead \& Connor, 2005) or the discreteness of food resources (Mitchell et al., 1991). In species where male cooperative mate guarding occurs, males clearly benefit from these social ties (Noë \& Sluijter, 1995; Watts, 1998; Connor et al., 2001). In primates, female use of social ties to monopolize food within groups is demonstrated via comparisons between populations with variable discreteness of food patches (Mitchell et al., 1991), however between female variation in the benefits of such ties may be more directly observable in the context of attaining the social power, or dominance, to have priority of access to food. For females in female-philopatric species, ties to establish, maintain, and increase dominance rank may be particularly important during development, as adult female rank is often stable (Clutton-Brock \& Huchard, 2013). Among males, coalitions to establish and increase social status are likely to be most important during adulthood (Duffy et al., 2007; Schülke et al., 2010; Gilby et al., 2013), however social integration (McDonald, 2007) and play experience 
(Pellis \& Pellis, 2007; Blumstein et al., 2013; Palagi, 2018) during development may influence behavioural competence relevant to navigating the adult male competitive environment.

The ability of ties to reduce risk and allostatic load via instrumental and buffering support may be the most comprehensive and multi-faceted pathway by which they influence fitness. An important alternative hypothesis to compare against this is that social interaction actually increases risks and allostatic load related to aggression and injury (Schino \& Alessandrini, 2015; Kalbitzer et al., 2017). Nevertheless, the short-term costs of association, like increased aggression received, may be outweighed by a longer-term benefit of a stable affiliative or cooperative tie. One common mechanism that allows ties to passively provide instrumental support is their ability to increase tolerance, allowing individuals to avoid harassment (Duffy et al., 2007; Haunhorst et al., 2017), peaceably co-feed (King et al., 2011; Tiddi et al., 2011; Haunhorst et al., 2017), share safer microhabitats from predators (Kalbitzer et al., 2017) and maintain bodily contact for warmth (McFarland et al., 2015). Ties also provide active instrumental support, such as when females form alliances to defend one another from abusive males (Sterck et al., 1997) or when individuals more effectively communicate the presence of a predator when more strongly bonded with each other (Micheletta \& Waller, 2012; Micheletta et al., 2012). Affiliative ties provide buffering support by creating stable and predictable environments during traumatic events (Crockford et al., 2008; Wittig et al., 2008; Young et al., 2014a; Wittig et al., 2016), possibly by increasing production of the anxiolytic oxytocin (Curley, 2011; Crockford et al., 2013). A final and straightforward way that ties provide buffering support is by preventing isolation. Isolation itself, rather than exposure to extreme temperatures and predators, seems to become a problem by means of increased allostatic load only in extreme cases, such as in humans and laboratory animals (Cacioppo \& Hawkley, 2003; Hawkley \& Cacioppo, 2010; Hawkley et al., 2012). In general, further research is necessary to understand whether sustained allostatic load as measured by GCs leads to decreased fitness in wild non-human animals (Bonier et al., 2009; Beehner \& Bergman, 2017). Measuring allostatic load as a composite index of primary and secondary allostatic biomarkers in non-human primates may aid in this endeavor (Maestripieri \& Hoffman, 2011; Edes \& Crews, 2017).

Finally, ties during development play a special role in developing behavioural competence and preparing individuals for their adult environments. 
Ties provide opportunities for social learning and additional motor-neural development in social play (Galef \& Laland, 2005; Taborsky \& Oliveira, 2012; Palagi, 2018). While ties' influence on social competence is clear from laboratory studies (e.g., Pellis \& Pellis, 2007; Arnold \& Taborsky, 2010), the challenge remains for more field studies to operationalize and evaluate competence. A further challenge is then to link behavioural competence with fitness outcomes. As ties during development are part of early life experience, the following competing hypotheses are important to compare: (1) early life social experiences influence behavioural competence, which in turn influences fitness outcomes, or (2) early life experiences influence behavioural competence and fitness simultaneously and independently. Support for the latter hypothesis would suggest that the relationship between sociality and fitness among adults is not entirely causal. Again, data spanning individuals' entire lifetimes will be vitally important to make this comparison.

In conclusion, over two short decades the question 'do social ties matter?' has rapidly transformed into 'how do social ties matter?' Primate behavioural ecologists at several long-term primate field sites are now poised to examine in greater detail the pathways along which social ties potentially influence fitness in their study species. It is clear that many researchers at several ongoing field sites are doing just that (Snyder-Mackler et al., 2016; Kalbitzer et al., 2017; Ostner \& Schülke, 2018). This comes, in part, after several theoretical advances concerning the costs and benefits of ties (Silk, 2002, 2007; Massen et al., 2010; Seyfarth \& Cheney, 2012; Cords \& Thompson, 2017; Ostner \& Schülke, 2018), the technology to monitor behavioural, genetic, and endocrinological states (Crofoot et al., 2010; Higham, 2016; SnyderMackler \& Lea, 2018), and the long-term data to evaluate fitness outcomes (Clutton-Brock \& Sheldon, 2010; Alberts, 2018). With strong hypotheses about the functions and benefits of social ties, tailored to specific study systems, evidence spanning several species will continue to elucidate how social tendencies and larger social organizations have come to evolve in primates.

\section{Acknowledgements}

I sincerely thank the following people for many insightful discussions and their constructive input on drafts of this review: Marina Cords, Dorothy Cheney, Larissa Swedell, James Higham, James Curley, Stephanie Fox, Drew Enigk, Mariska Kret and two anonymous reviewers. 


\section{References}

Alberts, S.C. (2012). Magnitude and sources of variation in male reproductive performance. - In: Evolution of primate societies (Mitani, J.C., Call, J., Kappeler, P., Palombit, R. \& Silk, J., eds). The University of Chicago Press, Chicago, IL, p. 412-431.

Alberts, S.C. (2018). Social influences on survival and reproduction: insights from a longterm study of wild baboons. - J. Anim. Ecol. 88: 47-66.

Allen, J.P., Porter, M., McFarland, C., McElhaney, K.B. \& Marsh, P. (2007). The relation of attachment security to adolescents' paternal and peer relationships, depression, and externalizing behavior. - Child Dev. 78: 1222-1239.

Almeling, L., Hammerschmidt, K., Sennhenn-Reulen, H., Freund, A.M. \& Fischer, J. (2016). Motivational shifts in aging monkeys and the origins of social selectivity. - Curr. Biol. 26: 1744-1749.

Altmann, J. (1974). Observational study of behavior: sampling methods. - Behaviour 49: 227-267.

Altmann, J. \& Alberts, S.C. (2003). Variability in reproductive success viewed from a lifehistory perspective in baboons. - Am. J. Hum. Biol. 15: 401-409.

Altmann, J. \& Alberts, S.C. (2005). Growth rates in a wild primate population: ecological influences and maternal effects. - Behav. Ecol. Sociobiol. 57: 490-501.

Altmann, S.A. (1991). Diets of yearling female primates (Papio cynocephalus) predict lifetime fitness. - Proc. Natl. Acad. Sci. USA 88: 420-423.

Archie, E.A., Tung, J., Clark, M., Altmann, J. \& Alberts, S.C. (2014). Social affiliation matters: both same-sex and opposite-sex relationships predict survival in wild female baboons. — Proc. Roy. Soc. Lond. B: Biol. Sci. 281: 20141261.

Arnold, C. \& Taborsky, B. (2010). Social experience in early ontogeny has lasting effects on social skills in cooperatively breeding cichlids. - Anim. Behav. 79: 621-630.

Arueti, M., Perach-Barzilay, N., Tsoory, M.M., Berger, B., Getter, N. \& Shamay-Tsoory, S.G. (2013). When two become one: the role of oxytocin in interpersonal coordination and cooperation. - J. Cognit. Neurosci. 25: 1418-1427.

Aureli, F., Cords, M. \& van Schaik, C. (2002). Conflict resolution following aggression in gregarious animals: a predictive framework. - Anim. Behav. 64: 325-343.

Bailey, I., Myatt, J.P. \& Wilson, A.M. (2013). Group hunting within the Carnivora: physiological, cognitive and environmental influences on strategy and cooperation. - Behav. Ecol. Sociobiol. 67: 1-17.

Barale, C.L., Rubenstein, D.I. \& Beehner, J.C. (2015). Juvenile social relationships reflect adult patterns of behavior in wild geladas. — Am. J. Primatol. 77: 1086-1096.

Barocas, A., Ilany, A., Koren, L., Kam, M. \& Geffen, E. (2011). Variance in centrality within rock hyrax social networks predicts adult longevity. — PLoS ONE 6: e22375.

Barrett, L. \& Henzi, S.P. (2002). Constraints on relationship formation among female primates. - Behaviour 139: 263-290.

Barrett, L. \& Henzi, S.P. (2006). Monkeys, markets and minds: biological markets and primate sociality. - In: Cooperation in primates and humans: mechanisms and evolution (Kappeler, P.M. \& van Schaik, C.P., eds). Springer, Berlin, p. 209-232. 
Bastian, M.L., Sponberg, A.C., Sponberg, A.C., Suomi, S.J. \& Higley, J.D. (2002). Longterm effects of infant rearing condition on the acquisition of dominance rank in juvenile and adult rhesus macaques (Macaca mulatta). — Dev. Psychobiol. 42: 44-51.

Beehner, J.C. \& Bergman, T.J. (2017). The next step for stress research in primates: to identify relationships between glucocorticoid secretion and fitness. - Horm. Behav. 91: 68-83.

Bell, H.C., Pellis, S.M. \& Kolb, B. (2010). Juvenile peer play experience and the development of the orbitofrontal and medial prefrontal cortices. - Behav. Brain Res. 207: 7-13.

Berghänel, A., Ostner, J., Schröder, U. \& Schülke, O. (2011). Social bonds predict future cooperation in male Barbary macaques, Macaca sylvanus. - Anim. Behav. 81: 11091116.

Berghänel, A., Schülke, O. \& Ostner, J. (2015). Locomotor play drives motor skill acquisition at the expense of growth: a life history trade-off. — Sci. Adv. 1: e1500451.

Bergman, T.J. (2010). Social relationships and social knowledge. - In: Encyclopedia of behavioral neuroscience (Koob, G., Le Moal, M. \& Thompson, R., eds). Academic Press, Oxford, p. 288-294.

Berman, C.M. (1982). The ontogeny of social relationships with group companions among free-ranging infant rhesus monkeys I. Social networks and differentiation. - Anim. Behav. 30: 149-162.

Best, E.C., Dwyer, R.G., Seddon, J.M. \& Goldizen, A.W. (2014). Associations are more strongly correlated with space use than kinship in female eastern grey kangaroos. Anim. Behav. 89: 1-10.

Biro, P.A. \& Stamps, J.A. (2008). Are animal personality traits linked to life-history productivity? - Trends Ecol. Evol. 23: 361-368.

Biro, P.A. \& Stamps, J.A. (2010). Do consistent individual differences in metabolic rate promote consistent individual differences in behavior? — Trends Ecol. Evol. 25: 653-659.

Blumstein, D.T., Chung, L.K. \& Smith, J.E. (2013). Early play may predict later dominance relationships in yellow-bellied marmots (Marmota flaviventris). — Proc. Roy. Soc. Lond. B: Biol. Sci. 280: 20130485.

Boesch, C. (2002). Cooperative hunting roles among Tai chimpanzees. - Human Nature 13: 27-46.

Bonier, F., Martin, P.R., Moore, I.T. \& Wingfield, J.C. (2009). Do baseline glucocorticoids predict fitness? - Trends Ecol. Evol. 24: 634-642.

Branchi, I., D’Andrea, I., Gracci, F., Santucci, D. \& Alleva, E. (2009). Birth spacing in the mouse communal nest shapes adult emotional and social behavior. - Physiol. Behav. 96: 532-539.

Branchi, I., Curley, J.P., D’Andrea, I., Cirulli, F., Champagne, F.A. \& Alleva, E. (2013). Early interactions with mother and peers independently build adult social skills and shape BDNF and oxytocin receptor brain levels. - Psychoneuroendocrinology 38: 522-532.

Bray, J., Emery Thompson, M., Muller, M.N., Wrangham, R.W. \& Machanda, Z.P. (2018). The development of feeding behavior in wild chimpanzees (Pan troglodytes schweinfurthii). — Am. J. Phys. Anthropol. 165: 34-46. 
Brent, L., Semple, S., Dubuc, C., Heistermann, M. \& MacLarnon, A. (2011). Social capital and physiological stress levels in free-ranging adult female rhesus macaques. - Physiol. Behav. 102: 76-83.

Brent, L.J., Heilbronner, S.R., Horvath, J.E., Gonzalez-Martinez, J., Ruiz-Lambides, A., Robinson, A.G., Skene, J.P. \& Platt, M.L. (2013). Genetic origins of social networks in rhesus macaques. - Sci. Rep. 3: 1042.

Brent, L.J.N. (2015). Friends of friends: are indirect connections in social networks important to animal behaviour? - Anim. Behav. 103: 211-222.

Brent, L.J.N., Ruiz-Lambides, A. \& Platt, M.L. (2017). Family network size and survival across the lifespan of female macaques. - Proc. Roy. Soc. Lond. B: Biol. Sci. 284: 20170515.

Brent, L.N., MacLarnon, A., Platt, M. \& Semple, S. (2012). Seasonal changes in the structure of rhesus macaque social networks. - Behav. Ecol. Sociobiol.: 1-11.

Bruck, J.N. (2013). Decades-long social memory in bottlenose dolphins. - Proc. Roy. Soc. Lond. B: Biol. Sci. 280: 20131726.

Bshary, R., Goudet, J., Hula, J., Van De Waal, E. \& Krutzen, M. (2012). Similarity in food cleaning techniques within matrilines in wild vervet monkeys. - PLoS ONE 7: e35694.

Byers, J.A. (1980). Play partner preferences in Siberian ibex, Capra ibex sibirica. - Ethology 53: 23-40.

Cacioppo, J.T. \& Hawkley, L.C. (2003). Social isolation and health, with an emphasis on underlying mechanisms. — Perspect. Biol. Med. 46: S39-S52.

Cacioppo, J.T., Hawkley, L.C., Norman, G.J. \& Berntson, G.G. (2011). Social isolation. — Ann. N.Y. Acad. Sci. 1231: 17-22.

Cairns, S.J. \& Schwager, S.J. (1987). A comparison of association indices. - Anim. Behav. 35: 1454-1469.

Cameron, E.Z., Setsaas, T.H. \& Linklater, W.L. (2009). Social bonds between unrelated females increase reproductive success in feral horses. — Proc. Natl. Acad. Sci. USA 106: 13850-13853.

Champagne, F.A. (2008). Epigenetic mechanisms and the transgenerational effects of maternal care. - Front. Endocrinol. 29: 386-397.

Champagne, F.A., Weaver, I.C., Diorio, J., Dymov, S., Szyf, M. \& Meaney, M.J. (2006). Maternal care associated with methylation of the estrogen receptor- $\alpha 1 \mathrm{~b}$ promoter and estrogen receptor- $\alpha$ expression in the medial preoptic area of female offspring. - Endocrinology 147: 2909-2915.

Chapais, B. (1995). Alliances as a means of competition in primates: evolutionary, developmental, and cognitive aspects. - Am. J. Phys. Anthropol. 38: 115-136.

Chapais, B. \& Gauthier, C. (2004). Juveniles outrank higher-born females in groups of longtailed macaques with minimal kinship. — Int. J. Primatol. 25: 429-447.

Cheney, D.L. (1992). Intragroup cohesion and intergroup hostility: the relation between grooming distributions and intergroup competition among female primates. - Behav. Ecol. 3: 334-345.

Cheney, D.L. \& Seyfarth, R.M. (2009). Stress and coping mechanisms in female primates. Adv. Stud. Behav. 39: 1-44. 
Cheney, D.L., Silk, J.B. \& Seyfarth, R.M. (2016). Network connections, dyadic bonds and fitness in wild female baboons. - Roy. Soc. Open Sci. 3: 160255.

Clay, Z. \& de Waal, F.B. (2013). Development of socio-emotional competence in bonobos. Proc. Natl. Acad. Sci. USA 110: 18121-18126.

Clutton-Brock, T. \& Huchard, E. (2013). Social competition and its consequences in female mammals. - J. Zool. 289: 151-171.

Clutton-Brock, T. \& Sheldon, B.C. (2010). Individuals and populations: the role of long-term, individual-based studies of animals in ecology and evolutionary biology. — Trends Ecol. Evol. 25: 562-573.

Connor, R., Heithaus, M. \& Barre, L. (2001). Complex social structure, alliance stability and mating access in a bottlenose dolphin 'super-alliance'. — Proc. Roy. Soc. Lond. B: Biol. Sci. 268: 263-267.

Connor, R.C. (2007). Dolphin social intelligence: complex alliance relationships in bottlenose dolphins and a consideration of selective environments for extreme brain size evolution in mammals. — Philos. Trans. Roy. Soc. Lond. B: Biol. Sci. 362: 587-602.

Connor, R.C., Smolker, R. \& Bejder, L. (2006). Synchrony, social behaviour and alliance affiliation in Indian Ocean bottlenose dolphins, Tursiops aduncus. — Anim. Behav. 72: 1371-1378.

Coppinger, R. \& Smith, C. (1989). A model for understanding the evolution of mammalian behavior. - In: Current mammalogy (Genoways, H., ed.). Plenum Press, New York, NY, p. 335-374.

Cords, M. (2002). Friendship among adult female blue monkeys (Cercopithecus mitis). Behaviour 139: 291-314.

Cords, M. (2012). The 30-year blues: what we know and don't know about life history, group size, and group fission of blue monkeys in the Kakamega Forest, Kenya. — In: Long-term field studies of primates (Kappeler, P. \& Watts, D., eds). Springer, Berlin, p. 289-312.

Cords, M. \& Thompson, N. (2017). Friendships, coalitions, and alliances. - In: APA handbook of comparative psychology (Call, J., Burghardt, G., Pepperberg, I., Snowdon, C. \& Zentall, T., eds). American Psychological Association, Washington, DC, p. 899-914.

Cowlishaw, G. \& Dunbar, R.I. (1991). Dominance rank and mating success in male primates. - Anim. Behav. 41: 1045-1056.

Creel, S. \& Creel, N.M. (1995). Communal hunting and pack size in African wild dogs, Lycaon pictus. - Anim. Behav. 50: 1325-1339.

Crockford, C., Wittig, R., Whitten, P., Seyfarth, R. \& Cheney, D. (2008). Social stressors and coping mechanisms in wild female baboons (Papio hamadryas ursinus). - Horm. Behav. 53: 254-265.

Crockford, C., Wittig, R., Langergraber, K., Ziegler, T., Zuberbühler, K. \& Deschner, T. (2013). Urinary oxytocin and social bonding in related and unrelated wild chimpanzees. — Proc. Roy. Soc. Lond. B: Biol. Sci. 280: 20122765.

Crofoot, M.C. \& Wrangham, R.W. (2010). Intergroup aggression in primates and humans: the case for a unified theory. - In: Mind the gap: tracing the origins of human universals (Kappeler, P.M. \& Silk, J., eds). Springer Berlin Heidelberg, Berlin, Heidelberg, p. 171195. 
Crofoot, M.C., Lambert, T.D., Kays, R. \& Wikelski, M.C. (2010). Does watching a monkey change its behaviour? Quantifying observer effects in habituated wild primates using automated radiotelemetry. - Anim. Behav. 80: 475-480.

Curley, J. \& Branchi, I. (2012). Ontogeny of stable individual differences: gene-environment and epigenetic mechanisms. - In: Animal personalities. Behavior, physiology, and evolution (Carere, C. \& Maestriperi, D., eds). Chicago University Press, Chicago, p. 279-316.

Curley, J.P. (2011). The mu-opioid receptor and the evolution of mother-infant attachment: theoretical comment on Higham et al. (2011). — Behav. Neurosci. 125: 273-278.

Davis, G.H., Crofoot, M.C. \& Farine, D.R. (2018). Estimating the robustness and uncertainty of animal social networks using different observational methods. - Anim. Behav. 141: 29-44.

de Waal, F.B. (1986). The integration of dominance and social bonding in primates. - Q. Rev. Biol.: 459-479.

Delpierre, C., Fantin, R., Barboza-Solis, C., Lepage, B., Darnaudéry, M. \& Kelly-Irving, M. (2016). The early life nutritional environment and early life stress as potential pathways towards the metabolic syndrome in mid-life? A lifecourse analysis using the 1958 British Birth cohort. — BMC Public Health 16: 815-833.

Di Bitetti, M.S. (2000). The distribution of grooming among female primates: testing hypotheses with the Shannon-Wiener diversity index. — Behaviour 137: 1517-1540.

Dingemanse, N.J., Both, C., Drent, P.J. \& Tinbergen, J.M. (2004). Fitness consequences of avian personalities in a fluctuating environment. - Proc. Roy. Soc. Lond. B: Biol. Sci. 271: 847-852.

Douhard, M., Plard, F., Gaillard, J.-M., Capron, G., Delorme, D., Klein, F., Duncan, P., Loe, L.E. \& Bonenfant, C. (2014). Fitness consequences of environmental conditions at different life stages in a long-lived vertebrate. — Proc. Roy. Soc. Lond. B: Biol. Sci. 281: 0276.

Drea, C.M. \& Carter, A.N. (2009). Cooperative problem solving in a social carnivore. Anim. Behav. 78: 967-977.

Duboscq, J., Neumann, C., Agil, M., Perwitasari-Farajallah, D., Thierry, B. \& Engelhardt, A. (2017). Degrees of freedom in social bonds of crested macaque females. - Anim. Behav. 123: 411-426.

Duffy, K.G., Wrangham, R.W. \& Silk, J.B. (2007). Male chimpanzees exchange political support for mating opportunities. — Curr. Biol. 17: R586-R587.

Durrell, J., Sneddon, I., O'Connell, N. \& Whitehead, H. (2004). Do pigs form preferential associations? - Appl. Anim. Behav. Sci. 89: 41-52.

Edes, A.N. \& Crews, D.E. (2017). Allostatic load and biological anthropology. — Am. J. Phys. Anthropol. 162: e23146.

Emery Thompson, M., Kahlenberg, S.M., Gilby, I.C. \& Wrangham, R.W. (2007). Core area quality is associated with variance in reproductive success among female chimpanzees at Kibale National Park. — Anim. Behav. 73: 501-512.

Engh, A.L., Esch, K., Smale, L. \& Holekamp, K.E. (2000). Mechanisms of maternal rank 'inheritance' in the spotted hyaena, Crocuta crocuta. - Anim. Behav. 60: 323-332. 
Engh, A.L., Beehner, J., Bergman, T., Whitten, P., Hoffmeiers, R., Seyfarth, R. \& Cheney, D. (2006a). Female hierarchy instability, male immigration and infanticide increase glucocorticoid levels in female chacma baboons. - Anim. Behav. 71: 1227-1237.

Engh, A.L., Beehner, J.C., Bergman, T.J., Whitten, P.L., Hoffmeier, R.R., Seyfarth, R.M. \& Cheney, D.L. (2006b). Behavioural and hormonal responses to predation in female chacma baboons (Papio hamadryas ursinus). - Proc. Roy. Soc. Lond. B: Biol. Sci. 273: 707-712.

Evans, K.E. \& Harris, S. (2008). Adolescence in male African elephants, Loxodonta africana, and the importance of sociality. - Anim. Behav. 76: 779-787.

Fagen, R. \& Fagen, J. (2004). Juvenile survival and benefits of play behaviour in brown bears, Ursus arctos. - Evol. Ecol. Res. 6: 89-102.

Fairbanks, L. (2003). Juvenile vervet monkeys: establishing relationships and practicing skills for the future. - In: Juvenile primates (Pereira, M. \& Fairbanks, L., eds). The University of Chicago Press, London, p. 211-227.

Fairbanks, L.A. (1990). Reciprocal benefits of allomothering for female vervet monkeys. Anim. Behav. 40: 553-562.

Fanshawe, J.H. \& Fitzgibbon, C.D. (1993). Factors influencing the hunting success of an African wild dog pack. - Anim. Behav. 45: 479-490.

Farine, D.R. (2017). A guide to null models for animal social network analysis. - Methods Ecol. Evol. 8: 1309-1320.

Farine, D.R. \& Whitehead, H. (2015). Constructing, conducting and interpreting animal social network analysis. - J. Anim. Ecol. 84: 1144-1163.

Farine, D.R., Aplin, L.M., Sheldon, B.C. \& Hoppitt, W. (2015). Interspecific social networks promote information transmission in wild songbirds. — Proc. Roy. Soc. Lond. B: Biol. Sci. 282: 2804.

Feldman, R., Gordon, I., Influs, M., Gutbir, T. \& Ebstein, R.P. (2013). Parental oxytocin and early caregiving jointly shape children's oxytocin response and social reciprocity. Neuropsychopharmacology 38: 1154-1162.

Foerster, S., McLellan, K., Schroepfer-Walker, K., Murray, C.M., Krupenye, C., Gilby, I.C. \& Pusey, A.E. (2015). Social bonds in the dispersing sex: partner preferences among adult female chimpanzees. — Anim. Behav. 105: 139-152.

Foster, E.A., Franks, D.W., Mazzi, S., Darden, S.K., Balcomb, K.C., Ford, J.K.B. \& Croft, D.P. (2012). Adaptive prolonged postreproductive life span in killer whales. - Science 337: 1313.

Fraser, O.N. \& Bugnyar, T. (2010). The quality of social relationships in ravens. - Anim. Behav. 79: 927-933.

Fraser, O.N., Schino, G. \& Aureli, F. (2008). Components of relationship quality in chimpanzees. - Ethology 114: 834-843.

Frère, C.H., Krützen, M., Mann, J., Connor, R.C., Bejder, L. \& Sherwin, W.B. (2010). Social and genetic interactions drive fitness variation in a free-living dolphin population. - Proc. Natl. Acad. Sci. 107: 19949-19954. 
Friant, S., Ziegler, T.E. \& Goldberg, T.L. (2016). Primate reinfection with gastrointestinal parasites: behavioural and physiological predictors of parasite acquisition. - Anim. Behav. 117: 105-113.

Galef, J.B.G. \& Laland, K.N. (2005). Social learning in animals: empirical studies and theoretical models. - Bioscience 55: 489-499.

Gilby, I.C., Brent, L.J., Wroblewski, E.E., Rudicell, R.S., Hahn, B.H., Goodall, J. \& Pusey, A.E. (2013). Fitness benefits of coalitionary aggression in male chimpanzees. - Behav. Ecol. Sociobiol. 67: 373-381.

Gilby, I.C., Machanda, Z.P., Mjungu, D.C., Rosen, J., Muller, M.N., Pusey, A.E. \& Wrangham, R.W. (2015). 'Impact hunters' catalyse cooperative hunting in two wild chimpanzee communities. — Philos. Trans. Roy. Soc. Lond. B: Biol. Sci. 370: 0005.

Gilby, I.C. \& Wrangham, R.W. (2008). Association patterns among wild chimpanzees (Pan troglodytes schweinfurthii) reflect sex differences in cooperation. - Behav. Ecol. Sociobiol. 62: 1831-1842.

Godde, S., Humbert, L., Côté, S.D., Réale, D. \& Whitehead, H. (2013). Correcting for the impact of gregariousness in social network analyses. - Anim. Behav. 85: 553-558.

Gomes, C.M., Mundry, R. \& Boesch, C. (2009). Long-term reciprocation of grooming in wild West African chimpanzees. — Proc. Roy. Soc. Lond. B: Biol. Sci. 276: 699-706.

Grafen, A. (1984). Natural selection, kin selection and group selection. — In: Behavioural ecology: an evolutionary approach (Krebs, J. \& Davies, N., eds). Blackwell Sciences, Oxford, p. 62-84.

Gunnar, M.R. (2017). Social buffering of stress in development: a career perspective. Perspect. Psychol. Sci. 12: 355-373.

Hamede, R.K., Bashford, J., McCallum, H. \& Jones, M. (2009). Contact networks in a wild Tasmanian devil (Sarcophilus harrisii) population: using social network analysis to reveal seasonal variability in social behaviour and its implications for transmission of devil facial tumour disease. - Ecol. Lett. 12: 1147-1157.

Hanneman, R. \& Riddle, M. (2005). Introduction to social network methods. - University of California, Riverside, CA.

Haunhorst, C.B., Heesen, M., Ostner, J. \& Schülke, O. (2017). Social bonds with males lower the costs of competition for wild female Assamese macaques. - Anim. Behav. 125: 51-60.

Hawkley, L.C. \& Cacioppo, J.T. (2010). Loneliness matters: a theoretical and empirical review of consequences and mechanisms. - Ann. Behav. Med. 40: 218-227.

Hawkley, L.C., Cole, S.W., Capitanio, J.P., Norman, G.J. \& Cacioppo, J.T. (2012). Effects of social isolation on glucocorticoid regulation in social mammals. - Horm. Behav. 62: 314-323.

Heintz, M.R., Murray, C.M., Markham, A.C., Pusey, A.E. \& Lonsdorf, E.V. (2017). The relationship between social play and developmental milestones in wild chimpanzees (Pan troglodytes schweinfurthii). — Am. J. Primatol. 79: e22716.

Hemelrijk, C.K. \& Ek, A. (1991). Reciprocity and interchange of grooming and 'support' in captive chimpanzees. - Anim. Behav. 41: 923-935. 
Hemelrijk, C.K., Meier, C. \& Martin, R.D. (1999). 'Friendship' for fitness in chimpanzees? - Anim. Behav. 58: 1223-1229.

Henzi, S.P., Lusseau, D., Weingrill, T., Schaik, C.P. \& Barrett, L. (2009). Cyclicity in the structure of female baboon social networks. - Behav. Ecol. Sociobiol. 63: 1015-1021.

Higham, J.P. (2016). Field endocrinology of nonhuman primates: past, present, and future. Horm. Behav. 84: 145-155.

Hill, K. (2002). Altruistic cooperation during foraging by the Ache, and the evolved human predisposition to cooperate. - Human Nature 13: 105-128.

Hill, R.A., Bentley, R.A. \& Dunbar, R.I.M. (2008). Network scaling reveals consistent fractal pattern in hierarchical mammalian societies. — Biol. Lett. 4: 748-751.

Hinde, R. (1976a). Interactions, relationships and social structure. — Man: 1-17.

Hinde, R. (1976b). On describing relationships. — J. Child Psychol. Psychiatr. 17: 1-19.

Holekamp, K.E., Smale, L., Berg, R. \& Cooper, S.M. (1997). Hunting rates and hunting success in the spotted hyena (Crocuta crocuta). - J. Zool. 242: 1-15.

Holekamp, K.E., Smale, L. \& Szykman, M. (1996). Rank and reproduction in the female spotted hyaena. - Journal of Reproduction and Fertility 108: 229-237.

Holt-Lunstad, J., Smith, T.B. \& Layton, J.B. (2010). Social relationships and mortality risk: a meta-analytic review. — PLoS Medicine 7: 1-20.

Höner, O.P., Wachter, B., Hofer, H., Wilhelm, K., Thierer, D., Trillmich, F., Burke, T. \& East, M.L. (2010). The fitness of dispersing spotted hyaena sons is influenced by maternal social status. - Nat. Commun. 1: 60.

Hoppitt, W.J.E. \& Farine, D.R. (2018). Association indices for quantifying social relationships: how to deal with missing observations of individuals or groups. - Anim. Behav. 136: $227-238$.

Horrocks, J. \& Hunte, W. (1983). Maternal rank and offspring rank in vervet monkeys: an appraisal of the mechanisms of rank acquisition. - Anim. Behav. 31: 772-782.

Ilany, A. \& Akçay, E. (2016). Social inheritance can explain the structure of animal social networks. - Nat. Comm. 7: 12084.

Isbell, L. \& Young, T. (2002). Ecological models of female social relationships in primates: similarities, disparities, and some directions for future clarity. — Behaviour 139: 177-202.

Jarrett, J.D., Bonnell, T.R., Young, C., Barrett, L. \& Henzi, S.P. (2018). Network integration and limits to social inheritance in vervet monkeys. - Proc. Roy. Soc. Lond. B: Biol. Sci. 285: 2668.

Kaburu, S.S.K., Paukner, A., Simpson, E.A., Suomi, S.J. \& Ferrari, P.F. (2016). Neonatal imitation predicts infant rhesus macaque (Macaca mulatta) social and anxiety-related behaviours at one year. - Sci. Rep. 6: 34997.

Kalbitzer, U., Bergstrom, M.L., Carnegie, S.D., Wikberg, E.C., Kawamura, S., Campos, F.A., Jack, K.M. \& Fedigan, L.M. (2017). Female sociality and sexual conflict shape offspring survival in a Neotropical primate. — Proc. Natl. Acad. Sci. USA 114: 1892-1897.

Kappeler, L. \& Meaney, M.J. (2010). Epigenetics and parental effects. - Bioessays 32: 818827. 
Kappeler, P.M., Cremer, S. \& Nunn, C.L. (2015). Sociality and health: impacts of sociality on disease susceptibility and transmission in animal and human societies. - Philos. Trans. Roy. Soc. Lond. B: Biol. Sci. 370: 20140116.

Kern, J.M. \& Radford, A.N. (2016). Social-bond strength influences vocally mediated recruitment to mobbing. - Biol. Lett. 12: 0648.

King, A., Clark, F. \& Cowlishaw, G. (2011). The dining etiquette of desert baboons: the roles of social bonds, kinship, and dominance in co-feeding networks. - Am. J. Primatol. 73: 768-774.

Koenig, A. (2002). Competition for resources and its behavioral consequences among female primates. — Int. J. Primatol. 23: 759-783.

Krause, J. \& Godin, J.-G.J. (1995). Predator preferences for attacking particular prey group sizes: consequences for predator hunting success and prey predation risk. - Anim. Behav. 50: 465-473.

Kulahci, I.G., Rubenstein, D.I., Bugnyar, T., Hoppitt, W., Mikus, N. \& Schwab, C. (2016). Social networks predict selective observation and information spread in ravens. - Roy. Soc. Open Sci. 3: 160256.

Kummer, H. (1978). On the value of social relationships to nonhuman primates: a heuristic scheme. - Social Science Information 17: 687-705.

Kutsukake, N. \& Clutton-Brock, T. (2010). Grooming and the value of social relationships in cooperatively breeding meerkats. — Anim. Behav. 79: 271-279.

Langergraber, K., Mitani, J. \& Vigilant, L. (2009). Kinship and social bonds in female chimpanzees (Pan troglodytes). — Am. J. Primatol. 71: 840-851.

Lehmann, J., Majolo, B. \& McFarland, R. (2016). The effects of social network position on the survival of wild Barbary macaques, Macaca sylvanus. - Behav. Ecol. 27: 20-28.

Lewis, S.E. \& Pusey, A.E. (1997). Factors influencing the occurrence of communal care in plural breeding mammals. - In: Cooperative breeding in mammals. Cambridge University Press, New York, NY, p. 335-363.

Lin, N. \& Michener, C.D. (1972). Evolution of sociality in insects. - Q. Rev. Biol. 47: 131159.

Madden, J.R. \& Clutton-Brock, T.H. (2009). Manipulating grooming by decreasing ectoparasite load causes unpredicted changes in antagonism. - Proc. Roy. Soc. Lond. B: Biol. Sci. 276: 1263-1268.

Maestripieri, D. (1999). Fatal attraction: interest in infants and infant abuse in rhesus macaques. - Am. J. Phys. Anthropol. 110: 17-25.

Maestripieri, D. \& Hoffman, C.L. (2011). Chronic stress, allostatic load, and aging in nonhuman primates. - Dev. Psychopathol. 23: 1187-1195.

Maestripieri, D., McCormack, K., Lindell, S.G., Higley, J.D. \& Sanchez, M.M. (2006). Influence of parenting style on the offspring's behaviour and CSF monoamine metabolite levels in crossfostered and noncrossfostered female rhesus macaques. - Behav. Brain Res. 175: 90-95.

Majolo, B., de Bortoli Vizioli, A. \& Lehmann, J. (2016). The effect of intergroup competition on intragroup affiliation in primates. - Anim. Behav. 114: 13-19. 
Manassa, R.P. \& McCormick, M.I. (2013). Social learning improves survivorship at a lifehistory transition. - Oecologia 171: 845-852.

Mann, J., Stanton, M.A., Patterson, E.M., Bienenstock, E.J. \& Singh, L.O. (2012). Social networks reveal cultural behaviour in tool-using dolphins. - Nat. Commun. 3: 980.

Margulis, S.W., Nabong, M., Alaks, G., Walsh, A. \& Lacy, R.C. (2005). Effects of early experience on subsequent parental behaviour and reproductive success in oldfield mice, Peromyscus polionotus. - Anim. Behav. 69: 627-634.

Massen, J.J.M., Sterck, E.H.M. \& De Vos, H. (2010). Close social associations in animals and humans: functions and mechanisms of friendship. - Behaviour 147: 1379-1412.

Massen, J.M. \& Sterck, E.M. (2013). Stability and durability of intra- and intersex social bonds of captive rhesus macaques (Macaca mulatta). — Int. J. Primatol. 34: 770-791.

McDonald, D.B. (2007). Predicting fate from early connectivity in a social network. — Proc. Natl. Acad. Sci. USA 104: 10910-10914.

McFarland, R. \& Majolo, B. (2013). Coping with the cold: predictors of survival in wild Barbary macaques, Macaca sylvanus. - Biol. Lett. 9: 0428.

McFarland, R., Fuller, A., Hetem, R.S., Mitchell, D., Maloney, S.K., Henzi, S.P. \& Barrett, L. (2015). Social integration confers thermal benefits in a gregarious primate. - J. Anim. Ecol. 84: 871-878.

McFarland, R., Murphy, D., Lusseau, D., Henzi, S.P., Parker, J.L., Pollet, T.V. \& Barrett, L. (2017). The 'strength of weak ties' among female baboons: fitness-related benefits of social bonds. - Anim. Behav. 126: 101-106.

Melis, A.P., Hare, B. \& Tomasello, M. (2006). Engineering cooperation in chimpanzees: tolerance constraints on cooperation. - Anim. Behav. 72: 275-286.

Micheletta, J. \& Waller, B.M. (2012). Friendship affects gaze following in a tolerant species of macaque, Macaca nigra. - Anim. Behav. 83: 459-467.

Micheletta, J., Waller, B.M., Panggur, M.R., Neumann, C., Duboscq, J., Agil, M. \& Engelhardt, A. (2012). Social bonds affect anti-predator behaviour in a tolerant species of macaque, Macaca nigra. — Proc. Roy. Soc. Lond. B: Biol. Sci. 279: 4042-4050.

Mitani, J.C. (2009). Male chimpanzees form enduring and equitable social bonds. - Anim. Behav. 77: 633-640.

Mitani, J.C., Merriwether, D.A. \& Zhang, C. (2000). Male affiliation, cooperation and kinship in wild chimpanzees. - Anim. Behav. 59: 885-893.

Mitani, J.C. \& Rodman, P.S. (1979). Territoriality: the relation of ranging pattern and home range size to defendability, with an analysis of territoriality among primate species. Behav. Ecol. Sociobiol. 5: 241-251.

Mitchell, C.L., Boinski, S. \& Van Schaik, C.P. (1991). Competitive regimes and female bonding in two species of squirrel monkeys (Saimiri oerstedi and S. sciureus). - Behav. Ecol. Sociobiol. 28: 55-60.

Mosser, A. \& Packer, C. (2009). Group territoriality and the benefits of sociality in the African lion, Panthera leo. - Anim. Behav. 78: 359-370.

Noë, R. \& Hammerstein, P. (1995). Biological markets. — Trends Ecol. Evol. 10: 336-339.

Noë, R. \& Sluijter, A.A. (1995). Which adult male savanna baboons form coalitions? — Int.

J. Primatol. 16: 77-105. 
Noe, R. \& Voelkl, B. (2013). Cooperation and biological markets: the power of partner choice. - In: Cooperation and its evolution (Sterelny, K., Krebs, R., Calcott, B. \& Fraser, B., eds). MIT Press, Cambridge, MA, p. 131.

Nunes, S. (2014). Juvenile social play and yearling behavior and reproductive success in female Belding's ground squirrels. - J. Ethol. 32: 145-153.

Nunes, S., Muecke, E.-M., Sanchez, Z., Hoffmeier, R. \& Lancaster, L. (2004). Play behavior and motor development in juvenile Belding's ground squirrels (Spermophilus beldingi). Behav. Ecol. Sociobiol. 56: 97-105.

Nuñez, C.M.V., Adelman, J.S. \& Rubenstein, D.I. (2015). Sociality increases juvenile survival after a catastrophic event in the feral horse (Equus caballus). - Behav. Ecol. 26: 138-147.

Öst, M., Smith, B.D. \& Kilpi, M. (2008). Social and maternal factors affecting duckling survival in eiders Somateria mollissima. - J. Anim. Ecol. 77: 315-325.

Öst, M., Ydenberg, R., Kilpi, M. \& Lindström, K. (2003). Condition and coalition formation by brood-rearing common eider females. - Behav. Ecol. 14: 311-317.

Ostner, J. \& Schülke, O. (2018). Linking sociality to fitness in primates: a call for mechanisms. - Adv. Stud. Behav. 50: 127-175.

Palagi, E. (2018). Not just for fun! Social play as a springboard for adult social competence in human and non-human primates. — Behav. Ecol. Sociobiol. 72: 90.

Palagi, E., Antonacci, D. \& Cordoni, G. (2007). Fine-tuning of social play in juvenile lowland gorillas (Gorilla gorilla gorilla). — Dev. Psychobiol. 49: 433-445.

Palombit, R.A. (2009). "Friendship" with males: a female counterstrategy to infanticide in chacma baboons of the Okavango Delta. - In: Sexual coercion in primates (Muller, M.N. \& Wrangham, R.W., eds). Harvard University Press, Cambridge, MA, p. 377-409.

Palombit, R.A., Seyfarth, R.M. \& Cheney, D.L. (1997). The adaptive value of 'friendships' to female baboons: experimental and observational evidence. — Anim. Behav. 54: 599-614.

Pellis, S.M. \& Pellis, V.C. (2007). Rough-and-tumble play and the development of the social brain. - Curr. Dir. Psychol. Sci. 16: 95-98.

Peres, C.A. (1989). Costs and benefits of territorial defense in wild golden lion tamarins, Leontopithecus rosalia. - Behav. Ecol. Sociobiol. 25: 227-233.

Pillay, N. \& Rymer, T.L. (2015). Alloparenting enhances the emotional, social and cognitive performance of female African striped mice, Rhabdomys pumilio. - Anim. Behav. 99: 43-52.

Pope, T.R. (2000). Reproductive success increases with degree of kinship in cooperative coalitions of female red howler monkeys (Alouatta seniculus). — Behav. Ecol. Sociobiol. 48: 253-267.

Pusey, A. (2012). Magnitude and sources of variation in female reproductive performance. In: Evolution of primate societies (Mitani, J., Call, J., Kappeler, P., Palombit, R. \& Silk, J., eds). Springer, Berlin, p. 343-366.

Pusey, A., Williams, J. \& Goodall, J. (1997). The influence of dominance rank on the reproductive success of female chimpanzees. - Science 277: 828-831.

Radford, A.N. \& du Plessis, M.A. (2004). Territorial vocal rallying in the green woodhoopoe: factors affecting contest length and outcome. - Anim. Behav. 68: 803-810. 
Réale, D., Garant, D., Humphries, M.M., Bergeron, P., Careau, V. \& Montiglio, P.-O. (2010). Personality and the emergence of the pace-of-life syndrome concept at the population level. — Philos. Trans. Roy. Soc. Lond. B: Biol. Sci. 365: 4051-4063.

Roelfs, D.J., Shor, E., Kalish, R. \& Yogev, T. (2011). The rising relative risk of mortality for singles: meta-analysis and meta-regression. — Am. J. Epidemiol. 174: 379-389.

Romero, L.M., Dickens, M.J. \& Cyr, N.E. (2009). The reactive scope model - a new model integrating homeostasis, allostasis, and stress. - Horm. Behav. 55: 375-389.

Ron, T., Henzi, S.P. \& Motro, U. (1996). Do female chacma baboons compete for a safe spatial position in a southern woodland habitat? - Behaviour 133: 475-490.

Ross, C. \& MacLarnon, A. (2000). The evolution of non-maternal care in anthropoid primates: a test of the hypotheses. - Folia Primatol. 71: 93-113.

Roth, A.M. \& Cords, M. (2016). Effects of group size and contest location on the outcome and intensity of intergroup contests in wild blue monkeys. - Anim. Behav. 113: 49-58.

Rothstein, A. \& Griswold, J.G. (1991). Age and sex preferences for social partners by juvenile bison bulls, Bison bison. - Anim. Behav. 41: 227-237.

Ruch, J., Herberstein, M. \& Schneider, J. (2014). Families hunt more successfully: effect of group composition on hunting and communal feeding. - Anim. Behav. 91: 171-178.

Sachser, N., Hennessy, M.B. \& Kaiser, S. (2011). Adaptive modulation of behavioural profiles by social stress during early phases of life and adolescence. - Neurosci. Biobehav. Rev. 35: 1518-1533.

Sand, H., Wikenros, C., Wabakken, P. \& Liberg, O. (2006). Effects of hunting group size, snow depth and age on the success of wolves hunting moose. - Anim. Behav. 72: 781789.

Sapolsky, R. (1986). Endocrine and behavioral correlates of drought in wild olive baboons (Papio anubis). - Am. J. Primatol. 11: 217-227.

Sapolsky, R. (2005). The influence of social hierarchy on primate health. - Science 308 : 648-652.

Sapolsky, R., Alberts, S. \& Altmann, J. (1997). Hypercortisolism associated with social subordinance or social isolation among wild baboons. - General Psychiatry 54: 11371143.

Sapolsky, R.M., Romero, L.M. \& Munck, A.U. (2000). How do glucocorticoids influence stress responses? Integrating permissive, suppressive, stimulatory, and preparative actions 1. - Endocr. Rev. 21: 55-89.

Schino, G. \& Alessandrini, A. (2015). Short-term costs and benefits of grooming in Japanese macaques. - Primates 56: 253-257.

Schino, G., Aureli, F., D’ Amato, F.R., D’Antoni, M., Pandolfi, N. \& Troisi, A. (1993). Infant kidnapping and co-mothering in Japanese macaques. — Am. J. Primatol. 30: 257-262.

Schneider, P., Bindila, L., Schmahl, C., Bohus, M., Meyer-Lindenberg, A., Lutz, B., Spanagel, R. \& Schneider, M. (2016). Adverse social experiences in adolescent rats result in enduring effects on social competence, pain sensitivity and endocannabinoid signaling. Front. Behav. Neurosci. 10: 203.

Schülke, O., Bhagavatula, J., Vigilant, L. \& Ostner, J. (2010). Social bonds enhance reproductive success in male macaques. - Curr. Biol. 20: 2207-2210. 
Schulkin, J. (2011). Evolutionary conservation of glucocorticoids and corticotropin releasing hormone: behavioral and physiological adaptations. - Brain Res. 1392: 27-46.

Seyfarth, R.M. (1977). A model of social grooming among adult female monkeys. J. Theor. Biol. 65: 671-698.

Seyfarth, R.M. \& Cheney, D.L. (2012). The evolutionary origins of friendship. - Annu. Rev. Psychol. 63: 153-177.

Seyfarth, R.M. \& Cheney, D.L. (2013). Affiliation, empathy, and the origins of theory of mind. — Proc. Natl. Acad. Sci. USA 110: 10349-10356.

Shor, E. \& Roelfs, D.J. (2015). Social contact frequency and all-cause mortality: a metaanalysis and meta-regression. - Soc. Sci. Med. 128: 76-86.

Silk, J., Alberts, S. \& Altmann, J. (2003). Social bonds of female baboons enhance infant survival. - Science 302: 1231-1234.

Silk, J., Alberts, S. \& Altmann, J. (2006). Social relationships among adult female baboons (Papio cynocephalus): II. Variation in the quality and stability of social bonds. - Behav. Ecol. Sociobiol. 61: 197-204.

Silk, J., Beehner, J., Bergman, T., Crockford, C., Engh, A., Moscovice, L., Wittig, R., Cheney, D. \& Seyfarth, R. (2009). The benefits of social capital: close social bonds among female baboons enhance offspring survival. — Proc. Roy. Soc. Lond. B: Biol. Sci. 276: 30993104.

Silk, J., Beehner, J., Bergman, T., Crockford, C., Engh, A., Moscovice, L., Wittig, R., Seyfarth, R. \& Cheney, D. (2010a). Female chacma baboons form strong, equitable, and enduring social bonds. — Behav. Ecol. Sociobiol. 64: 1733-1747.

Silk, J., Beehner, J., Bergman, T., Crockford, C., Engh, A., Moscovice, L., Wittig, R., Seyfarth, R. \& Cheney, D. (2010b). Strong and consistent social bonds enhance the longevity of female baboons. - Curr. Biol. 20: 1359-1361.

Silk, J., Cheney, D. \& Seyfarth, R. (2013). A practical guide to the study of social relationships. - Evol. Anthropol. 22: 213-225.

Silk, J.B. (2002). Using the 'F'-word in primatology. — Behaviour 139: 421-446.

Silk, J.B. (2007). The adaptive value of sociality in mammalian groups. - Philos. Trans. Royal Soc. B 362: 539-559.

Smale, L., Frank, L.G. \& Holekamp, K.E. (1993). Ontogeny of dominance in free-living spotted hyaenas: juvenile rank relations with adult females and immigrant males. Anim. Behav. 46: 467-477.

Smith, B. \& Wilson, J.B. (1996). A consumer's guide to evenness indices. - Oikos 76: 70-82.

Smith, J.E., Van Horn, R.C., Powning, K.S., Cole, A.R., Graham, K.E., Memenis, S.K. \& Holekamp, K.E. (2010). Evolutionary forces favoring intragroup coalitions among spotted hyenas and other animals. - Behav. Ecol. 21: 284-303.

Smuts, B. \& Smuts, R. (1993). Male aggression and sexual coercion of females in nonhuman primates and other mammals: evidence of theoretical implications. - Adv. Stud. Behav. 22: 1-63.

Snyder-Mackler, N. \& Lea, A.J. (2018). Functional genomic insights into the environmental determinants of mammalian fitness. - Curr. Opin. Genet. Dev. 53: 105-112. 
Snyder-Mackler, N., Sanz, J., Kohn, J.N., Brinkworth, J.F., Morrow, S., Shaver, A.O., Grenier, J.-C., Pique-Regi, R., Johnson, Z.P., Wilson, M.E., Barreiro, L.B. \& Tung, J. (2016). Social status alters immune regulation and response to infection in macaques. - Science 354: 1041-1045.

Spinka, M., Newberry, R.C. \& Bekoff, M. (2001). Mammalian play: training for the unexpected. - Q. Rev. Biol.: 141-168.

Stanford, C.B. (1992). Costs and benefits of allomothering in wild capped langurs (Presbytis pileata). - Behav. Ecol. Sociobiol. 30: 29-34.

Stanton, M.A. \& Mann, J. (2012). Early social networks predict survival in wild bottlenose dolphins. - PLoS ONE 7: e47508.

Sterck, E.H., Watts, D.P. \& van Schaik, C.P. (1997). The evolution of female social relationships in nonhuman primates. - Behav. Ecol. Sociobiol. 41: 291-309.

Strodl, M.A. \& Schausberger, P. (2012). Social familiarity reduces reaction times and enhances survival of group-living predatory mites under the risk of predation. - PLoS ONE 7: 0043590.

Surbeck, M. \& Hohmann, G. (2008). Primate hunting by bonobos at LuiKotale, Salonga National Park. - Curr. Biol. 18: R906-R907.

Surbeck, M., Mundry, R. \& Hohmann, G. (2011). Mothers matter! Maternal support, dominance status and mating success in male bonobos (Pan paniscus). — Proc. Roy. Soc. Lond. B: Biol. Sci. 278: 590-598.

Taborsky, B. \& Oliveira, R.F. (2012). Social competence: an evolutionary approach. Trends Ecol. Evol. 27: 679-688.

Taborsky, B., Arnold, C., Junker, J. \& Tschopp, A. (2012). The early social environment affects social competence in a cooperative breeder. — Anim. Behav. 83: 1067-1074.

Thompson, K.V. (1996). Play-partner preferences and the function of social play in infant sable antelope, Hippotragus niger. - Anim. Behav. 52: 1143-1155.

Thompson, N.A. \& Cords, M. (2018). Stronger social bonds do not always predict greater longevity in a gregarious primate. - Ecol. Evol. 8: 1604-1614.

Thompson, N.A., Higham, J.P., Heistermann, M., Vogel, E. \& Cords, M. (2019). Energy balance but not competitive environment corresponds with allostatic load during development in an Old World monkey. - Horm. Behav. 108: 30-41.

Tiddi, B., Aureli, F., Polizzi di Sorrentino, E., Janson, C.H. \& Schino, G. (2011). Grooming for tolerance? Two mechanisms of exchange in wild tufted capuchin monkeys. - Behav. Ecol. 22: 663-669.

Tung, J., Archie, E.A., Altmann, J. \& Alberts, S.C. (2016). Cumulative early life adversity predicts longevity in wild baboons. — Nature Commun. 7: 11181.

Uchino, B.N. (2004). Social support and physical health: understanding the health consequences of relationships. - Yale University Press, New Haven, CT.

Uchino, B.N. (2009). Understanding the links between social support and physical health: a life-span perspective with emphasis on the separability of perceived and received support. - Perspect. Psychol. Sci. 4: 236-255. 
Val-Laillet, D., Guesdon, V., von Keyserlingk, M.A.G., de Passillé, A.M. \& Rushen, J. (2009). Allogrooming in cattle: relationships between social preferences, feeding displacements and social dominance. - Appl. Anim. Behav. Sci. 116: 141-149.

van den Berg, C.L., Hol, T., Van Ree, J.M., Spruijt, B.M., Everts, H. \& Koolhaas, J.M. (1999). Play is indispensable for an adequate development of coping with social challenges in the rat. - Dev. Psychobiol. 34: 129-138.

van Schaik, C. \& Van Noordwijk, M. (1986). The hidden costs of sociality: intra-group variation in feeding strategies in Sumatran long-tailed macaques. — Behaviour 99: 296315.

van Schaik, C., Pradhan, D. \& Noordwijk, M. (2004). Mating conflict in primates: infanticide, sexual harassment and female sexuality. - In: Sexual selection in primates: new and comparative perspectives (Kappeler, P. \& van Schaik, C., eds). Cambridge University Press, Cambridge, p. 131-150.

Vander Wal, E., Festa-Bianchet, M., Réale, D., Coltman, D.W. \& Pelletier, F. (2014). Sexbased differences in the adaptive value of social behavior contrasted against morphology and environment. - Ecology 96: 631-641.

Vander Wal, E., Gagné-Delorme, A., Festa-Bianchet, M. \& Pelletier, F. (2015). Dyadic associations and individual sociality in bighorn ewes. - Behav. Ecol. 27: 560-566.

Vander Wal, E., Paquet, P.C. \& Andrés, J.A. (2012). Influence of landscape and social interactions on transmission of disease in a social cervid. - Mol. Ecol. 21: 1271-1282.

Ward, C., Bauer, E.B. \& Smuts, B.B. (2008). Partner preferences and asymmetries in social play among domestic dog, Canis lupus familiaris, littermates. — Anim. Behav. 76: 11871199.

Watts, D.P. (1998). Coalitionary mate guarding by male chimpanzees at Ngogo, Kibale National Park, Uganda. — Behav. Ecol. Sociobiol. 44: 43-55.

Watts, D.P. \& Mitani, J.C. (2001). Boundary patrols and intergroup encounters in wild chimpanzees. - Behaviour 138: 299-327.

Watts, D.P. \& Mitani, J.C. (2002). Hunting behavior of chimpanzees at Ngogo, Kibale National Park, Uganda. - Int. J. Primatol. 23: 1-28.

Weaver, A. \& de Waal, F. (2003). The mother-offspring relationship as a template in social development: reconciliation in captive brown capuchins (Cebus apella). - J. Comp. Psychol. 117: 101-110.

Weaver, A., Richardson, R., Worlein, J., de Waal, F. \& Laudenslager, M. (2004). Response to social challenge in young Bonnet (Macaca radiata) and pigtail (Macaca nemestrina) macaques is related to early maternal experiences. - Am. J. Primatol. 62: 243-259.

Weidt, A., Hofmann, S.E. \& König, B. (2008). Not only mate choice matters: fitness consequences of social partner choice in female house mice. - Anim. Behav. 75: 801-808.

Weidt, A., Lindholm, A.K. \& Koenig, B. (2014). Communal nursing in wild house mice is not a by-product of group living: females choose. — Naturwissenschaften 101: 73-76.

Wey, T.W., Burger, J.R., Ebensperger, L.A. \& Hayes, L.D. (2013). Reproductive correlates of social network variation in plurally breeding degus (Octodon degus). — Anim. Behav. 85: 1407-1414. 
Whitehead, H. \& Connor, R. (2005). Alliances I. How large should alliances be? - Anim. Behav. 69: 117-126.

Williams, J.M., Oehlert, G.W., Carlis, J.V. \& Pusey, A.E. (2004). Why do male chimpanzees defend a group range? - Anim. Behav. 68: 523-532.

Wilson, M.L., Kahlenberg, S.M., Wells, M. \& Wrangham, R.W. (2012). Ecological and social factors affect the occurrence and outcomes of intergroup encounters in chimpanzees. Anim. Behav. 83: 277-291.

Wiszniewski, J., Brown, C. \& Möller, L.M. (2012a). Complex patterns of male alliance formation in a dolphin social network. - J. Mammal. 93: 239-250.

Wiszniewski, J., Corrigan, S., Beheregaray, L.B. \& Möller, L.M. (2012b). Male reproductive success increases with alliance size in Indo-Pacific bottlenose dolphins (Tursiops aduncus). - J. Anim. Ecol. 81: 423-431.

Wittig, R., Crockford, C., Lehmann, J., Whitten, P., Seyfarth, R. \& Cheney, D. (2008). Focused grooming networks and stress alleviation in wild female baboons. - Horm. Behav. 54: $170-177$.

Wittig, R., Crockford, C., Weltring, A., Langergraber, K., Deschner, T. \& Zuberbuehler, K. (2016). Social support reduces stress hormone levels in wild chimpanzees across stressful events and everyday affiliations. — Nature Commun. 7: 13361.

Wolf, M., van Doorn, G.S., Leimar, O. \& Weissing, F.J. (2007). Life-history trade-offs favour the evolution of animal personalities. - Nature 447: 581-584.

Yang, W.J., Maldonado-Chaparro, A.A. \& Blumstein, D.T. (2016). A cost of being amicable in a hibernating mammal. - Behav. Ecol. 28: 11-19.

Yee, J.R., Cavigelli, S.A., Delgado, B. \& McClintock, M.K. (2008). Reciprocal affiliation among adolescent rats during a mild group stressor predicts mammary tumors and lifespan. - Psychosom. Med. 70: 1050-1059.

Young, C., Majolo, B., Heistermann, M., Schülke, O. \& Ostner, J. (2014a). Responses to social and environmental stress are attenuated by strong male bonds in wild macaques. Proc. Natl. Acad. Sci. USA 111: 18195-18200.

Young, C., Majolo, B., Schülke, O. \& Ostner, J. (2014b). Male social bonds and rank predict supporter selection in cooperative aggression in wild Barbary macaques. - Anim. Behav. 95: 23-32.

Zhou, W., Sornette, D., Hill, R. \& Dunbar, R. (2005). Discrete hierarchical organization of social group sizes. — Proc. Roy. Soc. Lond. B: Biol. Sci. 272: 439-444. 